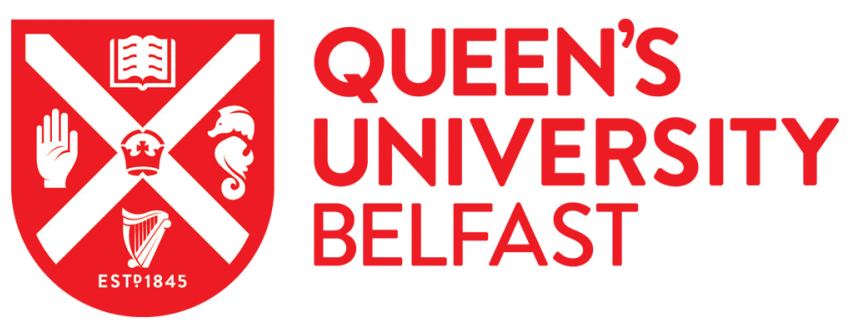

\title{
Evaluating the potential of natural surfactants in the petroleum industry: the case of hydrophobins
}

Blesic, M., Dichiarante, V., Milani, R., Linder , M., \& Metrangolo, P. (2018). Evaluating the potential of natural surfactants in the petroleum industry: the case of hydrophobins. Pure and Applied Chemistry, 90(2), 305-314. https://doi.org/10.1515/pac-2017-0703

\section{Published in:}

Pure and Applied Chemistry

\section{Document Version:}

Peer reviewed version

\section{Queen's University Belfast - Research Portal:}

Link to publication record in Queen's University Belfast Research Portal

\section{Publisher rights}

Copyright 2017 De Gruyter. This work is made available online in accordance with the publisher's policies. Please refer to any applicable terms of use of the publisher.

\section{General rights}

Copyright for the publications made accessible via the Queen's University Belfast Research Portal is retained by the author(s) and / or other copyright owners and it is a condition of accessing these publications that users recognise and abide by the legal requirements associated with these rights.

Take down policy

The Research Portal is Queen's institutional repository that provides access to Queen's research output. Every effort has been made to ensure that content in the Research Portal does not infringe any person's rights, or applicable UK laws. If you discover content in the Research Portal that you believe breaches copyright or violates any law, please contact openaccess@qub.ac.uk. 


\section{ICGC-6: Metrangolo P: Evaluating the potential of natural surfactants in the petroleum industry: The case of hydrophobins}

\begin{tabular}{|r|l|}
\hline Journal: & Pure and Applied Chemistry \\
\hline Manuscript ID & PAC-CON-17-07-03.R1 \\
\hline Manuscript Type: & Conference \\
\hline Complete List of Authors: & $\begin{array}{l}\text { Blesic, Marijana } \\
\text { Dichiarante, Valentina } \\
\text { Milani, Roberto } \\
\text { Linder, Markus } \\
\text { Metrangolo, Pierangelo }\end{array}$ \\
\hline Keywords: & Biosurfactant, Enhanced Oil Recovery (EOR), Hydrophobin, Emulsion \\
\hline Author-Supplied Keywords: & \\
\hline
\end{tabular}




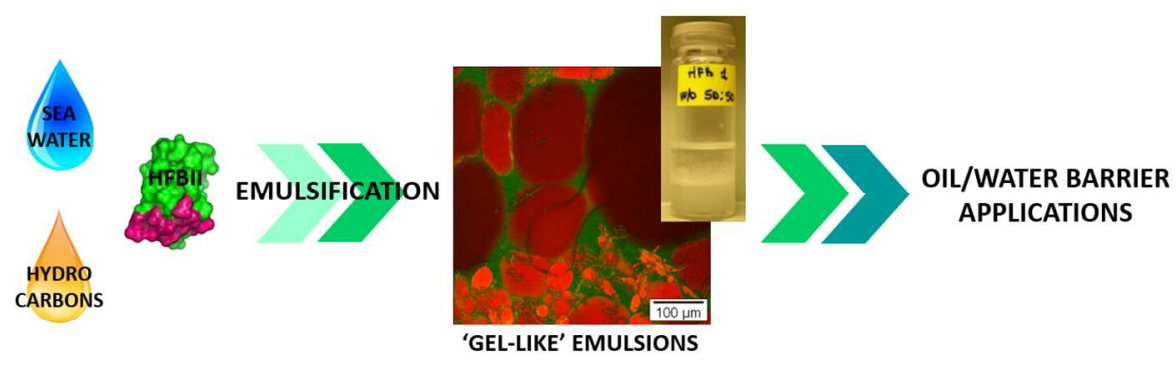

$252 \times 98 \mathrm{~mm}(150 \times 150 \mathrm{DPI})$ 


\title{
Evaluating the potential of natural surfactants in the petroleum industry:
} the case of hydrophobins

\begin{abstract}
Hydrophobins are fungal amphiphilic proteins with promising surface activity and emulsifying properties in oil well-like conditions, showing good potential as a green tool for oil/water barrier applications in the petroleum industry.
\end{abstract}




\title{
Evaluating the potential of natural surfactants in the petroleum industry: The case of hydrophobins
}

\author{
Marijana Blesic, ${ }^{1}$ Valentina Dichiarante, ${ }^{1}$ Roberto Milani, ${ }^{2}$ Markus Linder ${ }^{3}$ and Pierangelo \\ Metrangolo $\neq 1,2,3$
}

Abstract: Enhancing oil recovery from currently available reservoirs is a major issue for petroleum companies. Among the possible strategies towards this, chemical flooding through injection of surfactants into the wells seems to be particularly promising, thanks to their ability to reduce oil/water interfacial tension that promotes oil mobilization. Environmental concerns about the use of synthetic surfactants led to a growing interest in their replacement with surfactants of biological origin, such as lipopeptides and glycolipids produced by several microorganisms. Hydrophobins are small amphiphilic proteins produced by filamentous fungi with high surface activity and good emulsification properties, and may represent a novel sustainable tool for this purpose. We report here a thorough study of their stability and emulsifying performance towards a model hydrocarbon mixture, in conditions that mimic those of real oil reservoirs (high salinity and high temperature). Due to the moderate interfacial tension reduction induced in such conditions, the application of hydrophobins in enhanced oil recovery techniques does not appear feasible at the moment, at least in absence of cosurfactants. On the other hand, the obtained results showed the potential of hydrophobins in promoting the formation of a gel-like emulsion 'barrier' at the oil/water interface.

Keywords: Biosurfactant; Enhanced Oil Recovery (EOR); Hydrophobin; Emulsion.

\section{INTRODUCTION}

The last decades have shown a steady decrease in new oil fields discoveries. Moreover, current world oil reservoirs are mostly mature fields. In order to fulfill the energy demand in the next years, one of the major concerns for oil companies is thus to increase oil recovery from the available ageing resources.

Primary recovery, which is the first extraction step carried out without introducing other substances into the well, can recover only $12 \%$ to $15 \%$ of the oil. When the pressure inside the reservoir is no longer sufficient to expel the oil, water is usually injected to recover an additional $15 \%$ to $20 \%$ oil. This method is known as secondary oil recovery or water flooding. The remaining $60-70 \%$ of oil forms a discontinuous phase, with oil droplets trapped by capillary forces, which can be at least partially collected through a tertiary recovery process, known as Enhanced Oil Recovery (EOR). EOR techniques are classified in thermal processes, gas injection, and chemical flooding [1], [2].

As concerns the third strategy, viz. chemical flooding, injections of surfactants, polymers and alkali are generally used, especially in the case of sandstone reservoirs. Sometimes their combination is preferred to improve the recovery. Microemulsions (namely, transparent homogeneous mixtures of hydrocarbons and water with large amounts of surfactants), for example, proved to be an efficient tool in EOR techniques, thanks to their ability to reduce oil-water interfacial tension, thus leading to high extraction efficiency [3].

The use of surfactants seems a particularly promising chemical EOR approach to solve some of the most common needs of the petroleum industry, such as: (i) reduce the mixing of oil and water layers during the oil recovering from wells, through stabilization of oil-water separation; (ii) increase oil fluidity during transport through pipelines, by emulsification; (iii) facilitate the release of oil trapped in pores and/or adhered to surfaces in wells. Indeed, when an aqueous surfactant formulation is injected into a mature oil reservoir and contacts the small oil drops trapped in the pores of the reservoir rock, it reduces the interfacial tension and mobilizes the trapped oil by increasing the capillary number. Among all the available surfactants, anionic derivatives, e.g. sulfates and sulfonates, have been widely used for EOR purposes, in particular from sandstone rock matrices. Cationic amphiphiles have been rarely used, but they might be useful for oil extraction from positively charged carbonate rocks. Nonionic surfactants proved to be more tolerant towards high salinity than anionic ones, but are usually used as cosurfactants due to their lower ability to reduce interfacial activity [4].

Chemically synthesized surfactants are mainly petroleum-based, and have slow microbial degradation [5]. Therefore, they may bioaccumulate or give rise to environmentally hazardous by-products. Natural surfactants, also termed biosurfactants or microbial surface active agents, are amphiphilic compounds of biological origin produced by a variety of microorganisms -

\footnotetext{
1 Laboratory of Supramolecular and BioNano Materials (SupraBioNanoLab), Department of Chemistry, Materials, and Chemical Engineering "Giulio Natta", Politecnico di Milano, 20131 Milan, Italy; ${ }^{2}$ VTT-Technical Research Centre of Finland, 02150 Espoo, Finland;

${ }^{3}$ UNITWIN Network GREENOMIcS, Aalto University, 02150 Espoo, Finland.

${ }^{\ddagger}$ Corresponding author. E-mail: pierangelo.metrangolo@polimi.it
} 
including bacteria, yeasts, and fungi - from various substances and sometimes also from waste materials. They are usually classified into low molecular weight compounds (lipopeptides, glycolipids) and high molecular weight polymers [6]. Thanks to their unique properties, such as low toxicity, functionality under extreme conditions, biodegradable nature, and specific action, biosurfactants have several potential applications in the petroleum industry, mainly for the so-called Microbial Enhanced Oil Recovery (MEOR) [7], [8], [9]. Up to now, a major role in MEOR techniques was played by rhamnolipid, sophorolipid, glycolipid and lipopeptide biosurfactants [7]. Three main strategies can be adopted for using biosurfactants in EOR processes or mobilization of heavy oils: (i) direct injection of biosurfactant-producing microorganisms into the reservoir through the well, followed by their in situ multiplication through the reservoir rocks; (ii) ex situ injection of selected nutrients into a reservoir, to stimulate the growth of biosurfactant-producing microorganisms; (iii) external production of biosurfactants and their subsequent injection into the reservoir. Although glycolipids produced by Pseudomonas strains have been the most extensively used biosurfactants in MEOR experiments, lipopeptides - like surfactin and lichenysin - and lipid polysaccharide complexes were also found quite effective. Surfactin, a lipopeptide considered the most potent microbial surfactant known so far, was produced ex situ in a fermenter under controlled conditions and successfully used in MEOR [10].

Recently, a family of small Cysteine-rich amphiphilic proteins, called hydrophobins (HFBs), raised huge interest as novel biosurfactants and surface coating agents. HFBs are naturally produced in filamentous fungi and usually comprise about 100 amino acids, with molecular weights in the range of 7-15 kDa [11], [12], [13], [14]. According to the different clustering of hydrophobic and hydrophilic residues, they are grouped into Class I and Class II hydrophobins. At concentrations of few $\mu \mathrm{g} / \mathrm{mL}$, both classes of hydrophobins exist as monomers. At higher concentrations they form dimers. In a concentration range of $0.5-10 \mathrm{mg} / \mathrm{mL}$, tetramers or larger aggregates are formed [15]. At interfaces, Class II HFBs form monolayers with a significant degree of elasticity, whereas Class I proteins form multilayers. The good surface activity and exceptionally high surface elasticity of HFBs makes them the most surface-active proteins currently known, which promoted their successful exploitation in several different fields. Some of the uses proposed for HFBs include stabilization of foams and emulsions in the food industry [16], biotechnological applications such as drug delivery [17], [18], biomedical imaging [19] and coatings for biomedical devices [20], but also use as dispersing agents [21], [22] and intermediates for surface immobilization of proteins [23], [24] and polymers [25]. The ability of HFBs to self-assemble at oil-water interfaces and stabilize oil droplets makes them potential candidates for a more efficient and greener EOR strategy, also in consideration of the fact that the potential for large scale production of these proteins has been shown in industrial operations for both classes of HFBs [14], [16].

The present work focuses on HFBII, a Class II hydrophobin produced by Trichoderma reesei. Its reported crystal structure shows a nearly globular shape with a central $\beta$-barrel structure, a small segment of $\alpha$-helix, and an extended network of disulfide bonds stabilizing the structure [26], [27]. The protein surface is mainly hydrophilic, except for a flat 'hydrophobic patch' formed by two hairpin loops containing several aliphatic side chains. Such portion covers about $12 \%$ of HFBII total surface accessible area and is responsible of its amphiphilic behavior. HFBII has a molecular weight of about $7.2 \mathrm{kDa}$ and an isoelectric point between 6 and 7 [28]. This relatively small protein (less than $3 \mathrm{~nm}$ diameter) can lower the air/water surface tension to $35 \mathrm{mN} / \mathrm{m}$ at a concentration of $30 \mu \mathrm{M}$ [29].

To the best of our knowledge, the behaviour of HFBII in conditions relevant to petroleum industry applications has not been studied in depth, yet, and only a few patents were published on the subject. Patent CA 2642375, for example, describes a process for extracting hydrocarbons from oil sand with water and a hydrophobin [30]. Different $\mathrm{pH}$ and temperatures were screened, and a three-phase system was obtained in all cases. Hydrocarbons were found in all the phases (upper foam, aqueous middle and lower solid phases), although addition of hydrophobin increased the yield of hydrocarbons in the foam phase. Another patent (WO 2006/103253) claims the use of hydrophobins as auxiliary-emulsifying agents for a drilling fluid [31]. The reported drilling mud contained from 40 to $95 \%$ by weight of at least one oil component, from 2 to $60 \%$ by weight of water, and other components.

We report herein an exploratory study, aimed to establish whether HFBII holds promise as an additive in the petroleum industry, taking into consideration, for example, the influence exerted by seawater salinity or high temperatures on its emulsifying properties. We focused, in particular, on the following aspects: (i) possible formation of HFBII stable films at the water/oil interface, to create a barrier between the two phases; (ii) its performance as emulsifying agent, to disperse oil in water and increase its fluidity; (iii) the potential of this protein for Enhanced Oil Recovery.

\section{MATERIALS AND EXPERIMENTAL}

HFBII was obtained from T. reesei QM 9414 strain with a purity grade of about $98 \%$ (without HPLC purification) [32]. Synthetic seawater (SSW) was prepared by dissolving $24.53 \mathrm{~g}$ of $\mathrm{NaCl}, 4.09 \mathrm{~g}$ of $\mathrm{Na}_{2} \mathrm{SO}_{4}, 0.695 \mathrm{~g} \mathrm{of} \mathrm{KCl}, 1.16 \mathrm{~g}$ of $\mathrm{CaCl}_{2}$ and $5.20 \mathrm{~g}$ of $\mathrm{MgCl}_{2} \cdot 6 \mathrm{H}_{2} \mathrm{O}$ in $1 \mathrm{~L}$ of Milli-Q water (approximate salinity: $35 \mathrm{~g} / \mathrm{L}$ ). A high salinity water solution (approximate salinity: $70 \mathrm{~g} / \mathrm{L}$ ) was also prepared, doubling all salts concentrations. Dectol was prepared by mixing decane and toluene in 
65:35 volume ratio, and used as a 'model oil'. Emulsions were obtained by manual mixing, in order to mimic real mixing conditions. For rheology measurements and droplet size determination only, a high speed stator-rotor homogenizer (Heidolph DIAX 900) was used to provide better reproducibility.

For "Double Titration" experiments, five hydrophobin solutions in Milli-Q water with different concentrations of the protein $(5,7.5,10,15$ and $20 \mathrm{mg} / \mathrm{mL})$ were prepared. Titrations were done adding progressively small portions of the high salinity solution to hydrophobin solutions, until flocculation or precipitation occurred.

Tensiometric measurements at the SSW/dectol interface (pendant drop method) were performed on a CAM 200 (KSV Instruments Ltd.) and operated with the software CAM 2008 supplied with the instrument. Three different HFBII concentrations (1, 0.1 and $0.01 \mathrm{mg} / \mathrm{mL}$ ) were tested.

Emulsion 'bulk' rheology was measured with an AR G2 rheometer with parallel plate geometry (TA Instruments Ltd). Interfacial shear rheology was measured using a Du Noüy ring (1.2 cm diameter) oscillating in plane. Du Noüy ring connected to AR-G2 rheometer is commonly used for sensitive interfacial measurements, because of its low inertia and its capability to control and apply tiny torques. The Du Noüy ring was attached to the stress motor, mounted on the slide of the rheometer. A circular glass dish was located in the centre of the Peltier plate. Viscoelasticity of the selected emulsions was characterized by measuring their storage modulus (G') and loss modulus (G',') in the linear viscoelastic region, keeping the frequency constant at 0.1 Hz. Samples with 50:50 w/o ratio and different HFBII concentrations were analysed $48 \mathrm{~h}$ after emulsification.

The emulsification index $\mathrm{E}_{24}$ was determined according to a reported procedure [33]. In a typical experiment, dectol (6 $\mathrm{mL}$ ) was added to the biosurfactant solution $(4 \mathrm{~mL})$ in a graduated tube, vortexed at high speed for 2 minutes, and then left standing for $24 \mathrm{~h}$. The emulsification index was calculated dividing the final height of the emulsion layer by the total height, and multiplying by 100 .

Microscopy analyses were performed on an Olympus BX40 optical microscope (Olympus, Center Valley, Pennsylvania, USA) and a Zeiss LSM 710 microscope with a He/Ne laser $\left(\lambda_{\mathrm{ex}}=543 \mathrm{~nm}\right)$ using contrast phase, bright field and confocal microscopy techniques. Droplet size determination was calculated from the optical microscopy images from an average of ca. 2000 droplets. In confocal microscopy images specific dyes were used to stain oil and protein, namely Nile Red for oil phase and fluorescein isothiocyanate for HFBII.

\section{RESULTS AND DISCUSSION}

\section{Preliminary stability studies}

First, the stability of HFBII in SSW was evaluated by means of flocculation studies, varying different parameters. Double titration experiments were carried out at room temperature $\left(20^{\circ} \mathrm{C}\right)$ to establish the relationship between HFBII stability and salt concentration. After the addition of a certain volume of SSW to HFBII solutions, flocculation or precipitation of the protein occurred for all selected concentrations. In this process, the following behaviour was observed: i) appearance of a strong opalescence, ii) appearance of flakes in solution, iii) precipitation of a white solid. In Figure 1a, the final point of each series represents its 'flocculation point'. The curve connecting such points gives an indication of the protein stability and solubility at different salinity levels. Salinity actually affects the protein solubility in aqueous media, but not to a point as to prevent its use.

A similar set of experiments was performed at 40 and $70^{\circ} \mathrm{C}$, to test the influence of temperature on HFBII stability in SSW. As shown in Figure $1 \mathrm{~b}$, the protein behaviour did not change at $40{ }^{\circ} \mathrm{C}$, whereas at $70{ }^{\circ} \mathrm{C}$ a significant solubility increase was observed.

It should be noticed that HFBII flocculation is a slow kinetic process. The reported flocculation points refer to short times, but precipitation can occur even at lower protein concentration or salinities, if enough time is given, particularly under the effect of shear forces. 

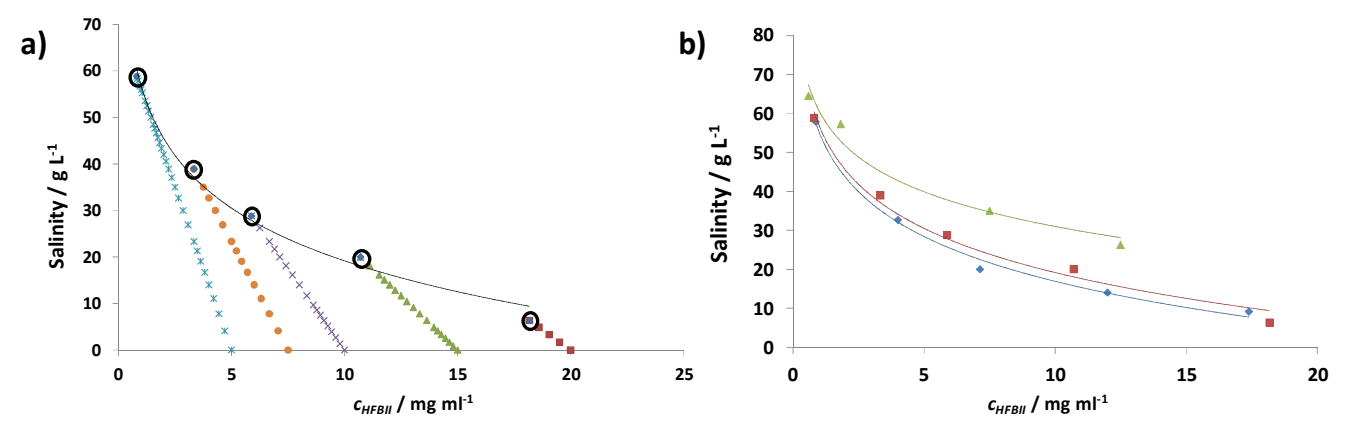

Fig. 1. a) Titration curves, showing salinity values versus different HFBII concentrations: $5(*), 7.5(\bullet), 10(\times), 15\left(\_\right)$, and 20 $\mathrm{mg} / \mathrm{mL}(\square)$. Flocculation points for each series are marked with a black circle. b) Flocculation points obtained at different temperatures, varying HFBII concentration: $20^{\circ} \mathrm{C}(\boldsymbol{\bullet}), 40^{\circ} \mathrm{C}(\star)$, and $70^{\circ} \mathrm{C}(\Delta)$.

Comment [VD1]: Figure 1 has been revised for uniformity as requested by Reviewer 1.

\section{Film formation}

To verify if HFBII still forms films in SSW as it does in low salinity aqueous media [34], [35], and how strong these films are, we measured first the interfacial tension reduction at the SSW/dectol interface through pendant drop measurements. The results confirmed that the protein works in SSW as it does in low salinity water. Compared to the value measured for SSW (about 37 $\mathrm{mN} / \mathrm{m}$ ), both $1 \mathrm{mg} / \mathrm{mL}$ and $0.1 \mathrm{mg} / \mathrm{mL}$ HFBII concentrations in SSW are able to reduce the surface tension until $15-16 \mathrm{mN} / \mathrm{m}$ (Figure 2). Reduction occurred instantly, although the interfacial tension kept on decreasing very slowly over time. This is consistent with the typical mechanism of HFB self-assembly, which involves first fast protein adsorption at the oil/water interface, followed by slow structural rearrangement of the adsorbed hydrophobin layer into closer packing [34].

Unfortunately the reduction of interface tension obtained with HFBII does not lead to the ultralow values typically needed in EOR applications $(<1 \mathrm{mN} / \mathrm{m})$, indicating that HFBII holds little promise in this sense, at least in the absence of a suitable co-surfactant. The addition of medium chain alcohols such as propan-2-ol, butanol or isoamyl alcohol, for example, has been shown to facilitate the preparation of microemulsions suitable for EOR [3], [36].

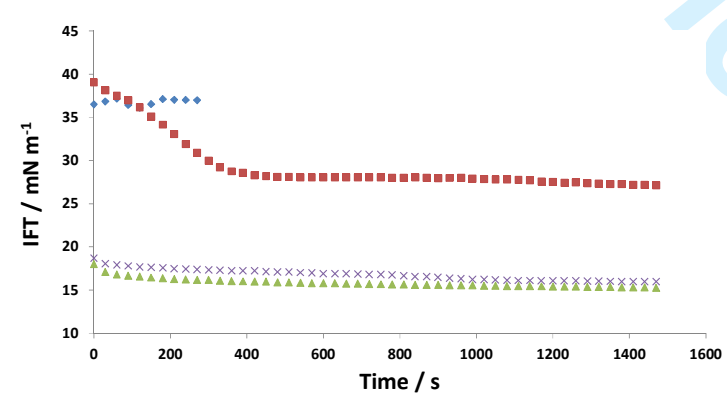

Fig. 2. Interfacial tension trends over time for SSW solutions of HFBII at different protein concentrations: $0(\star), 0.01(\varpi), 0.1(\Delta)$, and $1 \mathrm{mg} / \mathrm{mL}(\times)$.

Interfacial shear rheology measurements (Figure 3) showed that the film formed at the SSW/dectol interface is remarkably strong and elastic. Salinity did not seem to affect the film strength, which was comparable to that observed at water/oil and water/air interfaces. This can be promising for barrier applications. 
a)

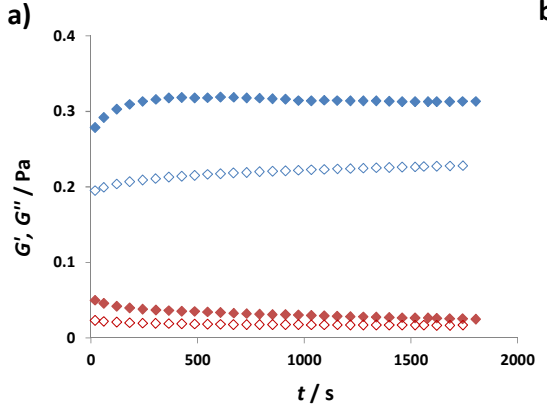

b)

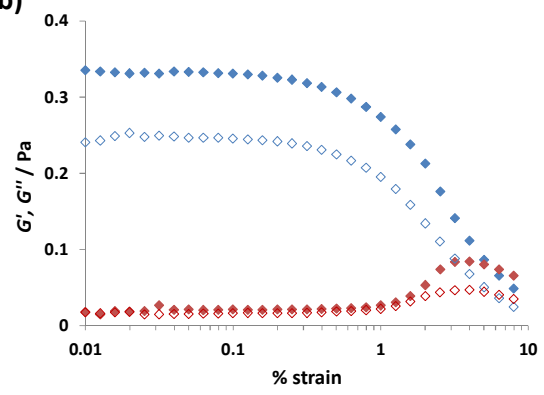

Fig. 3. Air-SSW (solid diamonds) and Dectol-SSW (empty diamonds) interfacial shear moduli G' (blue series) and $G$ ', (red series), measured at $0.05 \mathrm{mg} / \mathrm{mL}$ HFBII concentration and $0.1 \mathrm{~Hz}$ frequency, as a function of: a) time (with $0.5 \%$ strain); b) strain.

\section{Emulsification studies}

A systematic study of the emulsification of the SSW/dectol mixture in the presence of HFBII was performed, to verify the impact of several relevant parameters on the emulsification ability of the protein. The rheological properties of these emulsions were also studied, since a thick, resistant emulsion layer could favour the separation between oil and water.

First, the emulsification index $\mathrm{E}_{24}$ of HFBII in Milli-Q/dectol systems was measured, and compared to those of several ionic and non-ionic commercially available surfactants. HFBII performed well, showing an emulsification index in line with those observed for some of the best performing emulsifiers, such as Brij 58 and Didecyl-Dimethyl-Ammonium Chloride (Table 1).

Table 1

\begin{tabular}{lll}
\hline Surfactant & Class & $\mathbf{E}_{\mathbf{2 4}}$ \\
\hline HFBII & Protein & 74 \\
Didecyl-Dimethyl-Ammonium Chloride & Cationic & 81 \\
Sodium Dodecyl Sulfate & Anionic & 34 \\
Brij 58 & Nonionic & 78 \\
Triton X-100 & Nonionic & 21 \\
Tween 80 & Nonionic & 10 \\
Tergitol NP-9 & Nonionic & 3 \\
Span 85 & Nonionic & 0 \\
\hline
\end{tabular}

To clarify the influence of salinity on HFBII/oil emulsions, two samples were prepared dissolving the same amount of HFBII in SSW and Milli-Q water, respectively, with a 50:50 o/w ratio. As shown in Figure 4, both visual inspection and contrast phase microscopy confirmed the presence of significant differences in emulsion structure and thickness, as well as in oil droplets distribution. The emulsion layer of dectol in SSW was clearly less thick than that prepared in Milli-Q water, and displayed droplets with smaller maximum size and reduced size variability. Although high salinity reduced the emulsifying power of hydrophobin, the protein was still able to form emulsions. 

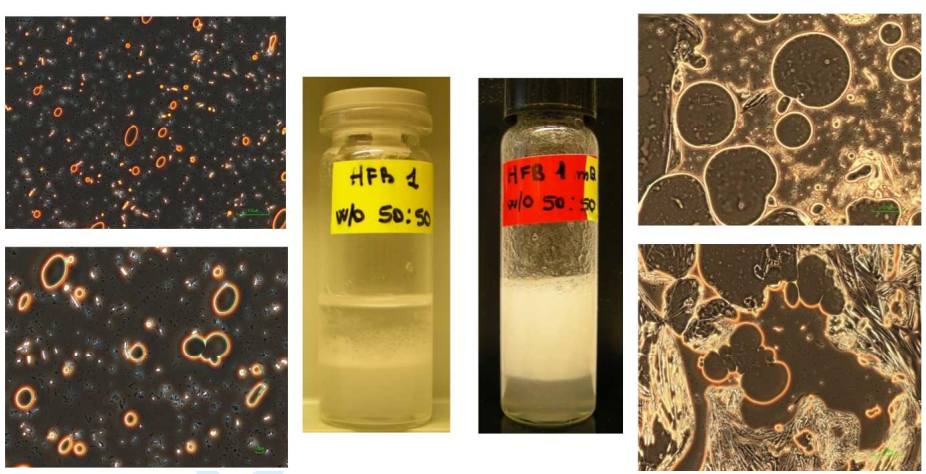

Fig. 4. Pictures and contrast phase microscopy images of 50:50 o/w emulsions obtained from $1 \mathrm{mg} / \mathrm{mL}$ HFBII solutions in SSW (left) and Milli-Q water (right).

The effect of temperature on emulsion stability was evaluated using the following procedure: a 50:50 mixture of dectol and 1 $\mathrm{mg} / \mathrm{mL}$ aqueous solution of HFBII was homogenized for 3 minutes, then kept at different temperatures $\left(20^{\circ} \mathrm{C}, 40{ }^{\circ} \mathrm{C}\right.$ and 70 ${ }^{\circ} \mathrm{C}$ ) for $2.5 \mathrm{~h}$ in a thermostatic bath, and centrifuged. Microscopy analyses showed no significant changes in the mean volumesurface radius $\left(\mathrm{R}_{32}\right)$ or relative height of the emulsion phase (Figure 5), meaning that thermal treatment of the emulsions did not affect the protein emulsifying properties.

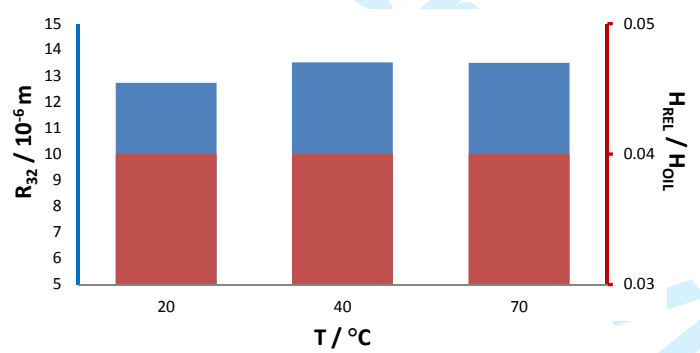

Fig. 5. Effect of thermal treatment at different temperatures on mean volume-surface radius $\left(\mathrm{R}_{32}\right.$, blue) and relative volume of oil released from emulsions after centrifugation $\left(\mathrm{H}_{\mathrm{REL}} / \mathrm{H}_{\mathrm{OIL}}, \mathrm{red}\right)$.

Further experiments were carried out to assess the effect of HFBII concentration and water/oil ratio. A set of five different HFBII concentrations $(0.1,0.25,0.5,0.75$, and $1 \mathrm{mg} / \mathrm{mL})$ in SSW were mixed with dectol in five different w/o ratios $(1: 9,3: 7$, 1:1, 7:3, 9:1) for 2 minutes with a high speed homogenizer. After $24 \mathrm{~h}$ resting, we measured the volumes of the obtained layers.

For a constant w/o ratio the curves of the relative emulsified volume $\mathrm{V}_{\mathrm{em}} / \mathrm{V}_{\text {oil }}$ vs. HFBII concentration showed a trend of slight increase at lower surfactant concentrations, i.e., in the region between the $\mathrm{y}$ axis and the green line. This indicates that HFBII concentrations of about $0.5 \mathrm{mg} / \mathrm{mL}$ (effective concentration on total mixture volume) are necessary to reach a maximum in the relative emulsified volume (Figure 6a), and that further addition of protein would not lead to any significant increase. Bright field optical microscopy images revealed that below $0.5 \mathrm{mg} / \mathrm{mL}$ HFBII concentration, emulsions with a uniform size distribution cannot be obtained (Figure 6b). Above this threshold value the average droplet size can be controlled by varying the protein concentration, as shown by the analysis of the mean volume-surface ratio $R_{32}$ of the oil droplets (Figure $6 \mathrm{c}$ ), and the emulsions were relatively monodisperse (Figure $6 \mathrm{~d}$ ).

The results also indicated that $w / o$ ratios $\geq 0.5$ are necessary to obtain a two-phase regime rather than three phases (Figure 6a). The two-phase system is not a typical Winsor type II system. While there is indeed an upper emulsion phase and a lower aqueous phase, the emulsion is however of the oil-in-water type rather than water-in-oil, and it is actually a miniemulsion rather than a microemulsion [4]. Indeed by staining the protein with fluorescein isothiocyanate and the oil phase with Nile Red, it was possible to see in confocal microscopy images that the samples are consistently oil-in-water emulsions, and that HFBII is present both in the bulk aqueous solution and as films connecting the oil droplets, which, however, do not coalesce (Figure $6 e)$. 
a) 3.0
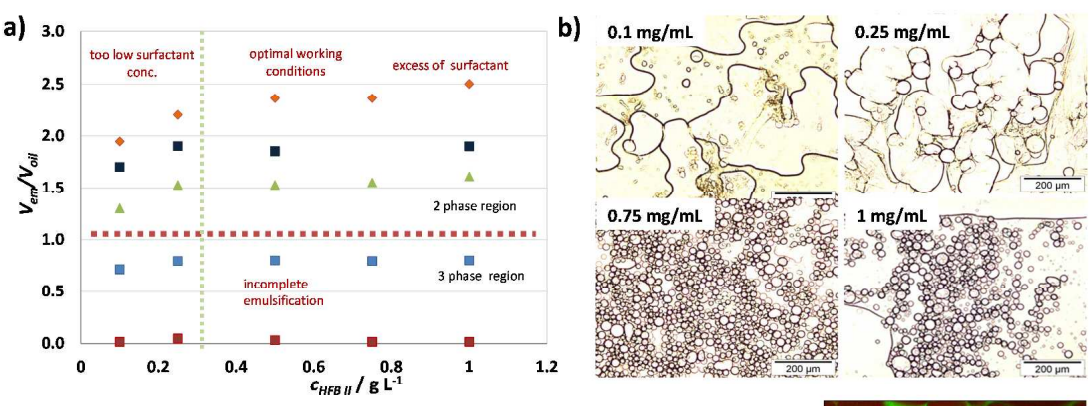

d)

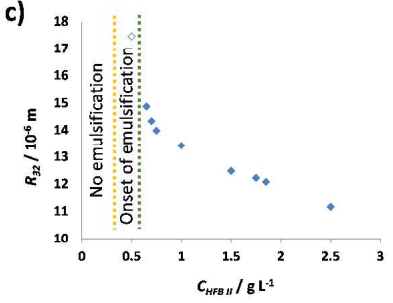

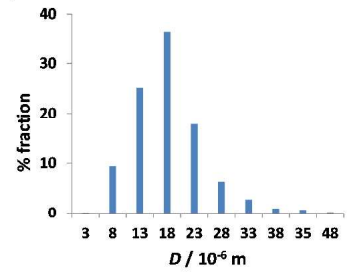

e)

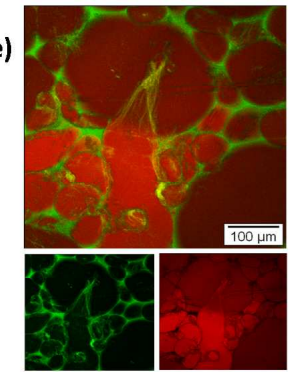

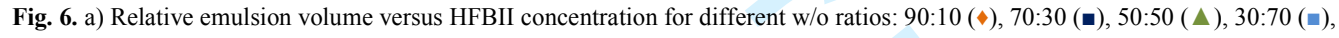
10:90 (匹). b) Bright field microscopy images of 1:1 w/o mixtures with increasing HFBII concentrations. c) Mean volume-surface radius as a function of hydrophobin concentration. d) Average droplet size distribution for $1 \mathrm{mg} / \mathrm{mL}$ HFBII concentration. e) Confocal microscopy images of 4:1 w/o emulsions with $1 \mathrm{mg} / \mathrm{mL}$ HFBII (green staining: protein; red staining: oil phase).

We studied the rheology of bulk emulsions at three different concentrations of HFBII, with a constant 1:1 w/o ratio and after a $48 \mathrm{~h}$ resting time (Figure 7a). For HFBII concentrations of 0.5 and $1 \mathrm{mg} / \mathrm{mL}$ the emulsions behave like gels (G' >> G'), with higher strength compared to other surfactants such as Brij and sodium dodecyl sulfate (SDS, Figure 7b). The significantly higher values obtained for the storage modulus G', compared to the loss modulus G', revealed that such emulsions had predominantly elastic (solid-like) behaviour. A minimum concentration of $0.5 \mathrm{mg} / \mathrm{mL}$ hydrophobin was needed to have relatively strong emulsion layers, as confirmed by the much lower G' value found for $0.25 \mathrm{mg} / \mathrm{mL}$ HFBII concentration, which only formed a weak gel, and in agreement with the results of the emulsification studies exposed above. This gel-like behaviour of hydrophobin emulsions is not promising for EOR applications or for oil fluidification through emulsification, but could be useful for the formation of an oil/water barrier. However, it should be noted that also in this case the use of a co-surfactant like a short or medium-chain alcohol might lead to a reduction of the tendency to form rigid structures, as previously shown for microemulsions targeted at EOR [3]. In addition, previous literature demonstrated that alcohols can affect the assembly of hydrophobins by stabilizing their monomeric form over the formation of aggregates [37], which might indeed lead to less rigid protein films. 
a)

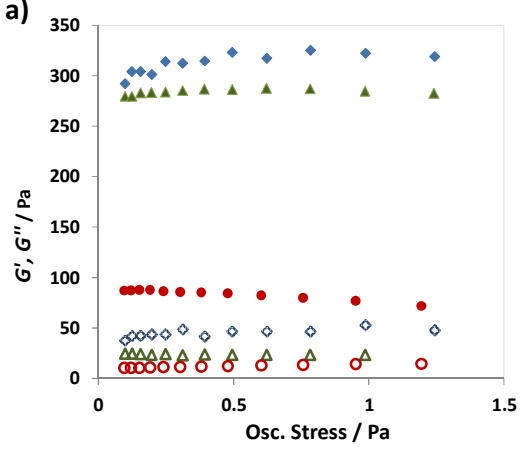

b)

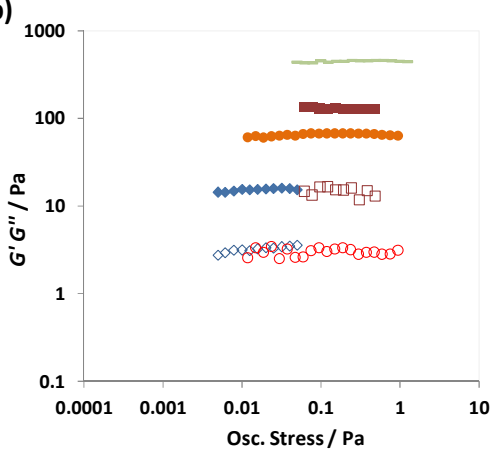

Fig. 7. Stress dependence of emulsion storage (G', solid symbols) and loss modulus ( $G$ ', empty symbols) in the near viscoelastic region: a) comparison among different HFBII concentrations: $0.25(\bullet), 0.5(\Delta)$, and $1 \mathrm{mg} / \mathrm{mL}(\star) ; b)$ comparison among different surfactants: Brij $1 \mathrm{mg} / \mathrm{mL}(\bullet), \operatorname{SDS} 2 \mathrm{mg} / \mathrm{mL}(\bullet), \operatorname{SDS} 3 \mathrm{mg} / \mathrm{mL}(\bullet)$, and HFBII $2.5 \mathrm{mg} / \mathrm{mL}(-)$.

These and previous results are summarized in the phase diagram shown in Figure 8, which illustrates the different behaviour regimes for SSW/dectol emulsions (Figure 8). For very low water content $(\mathrm{w} / \mathrm{o}=1: 9)$, stable emulsions cannot be formed. At slightly higher water content $(w / o=3: 7)$ three layers were detected: aqueous phase, emulsion and oil phase. This region (below the red line in Figure 6a) represents a regime of incomplete emulsification. For even higher water content the presence of only two phases was found (above the red line in Figure 6a), thus indicating complete oil emulsification. Here the volume of the emulsion layer is higher than the volume of the starting oil layer, and a higher water content results in higher relative volume of the emulsion layer. At these higher w/o ratios the rheological properties of the obtained emulsions depend essentially on HFBII concentration, behaving as weak emulsions roughly below $0.5 \mathrm{mg} / \mathrm{mL}$, and more like strong gels above this concentration.

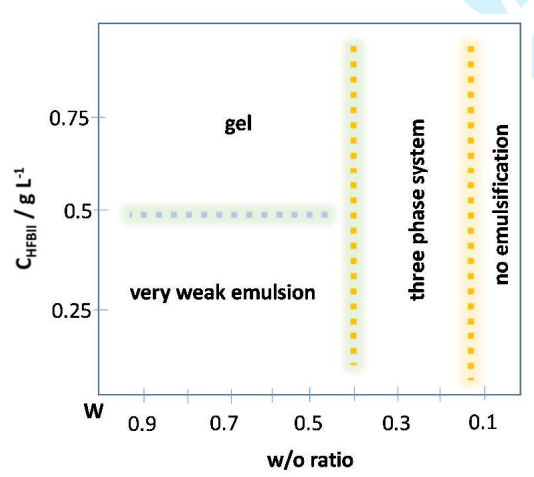

Fig. 8. Phase behaviour diagram of the studied emulsions, as a function of protein concentration $\left(\mathrm{C}_{\mathrm{HFB}}\right)$ and $\mathrm{w} / \mathrm{o}$ ratio.

\section{CONCLUSIONS}

Even though the high salinity and temperature conditions typical of oil recovery might be detrimental to its performance as a surfactant, the hydrophobin HFBII proved to still be able to form films and relatively strong emulsions in SSW up to $70{ }^{\circ} \mathrm{C}$, and its emulsifying power compared favourably to other surfactants. In spite of this, HFBII did not seem particularly promising for EOR and oil fluidification through emulsification, due to insufficient interface tension reduction and to the tendency to form gel-like miniemulsions. It is, however, worth noticing that the choice of an appropriate co-surfactant (e.g. medium chain alcohols) may improve HFBII performance in terms of EOR, both by facilitating microemulsion formation and by reducing the tendency to form a rigid gel-like structure. Furthermore, the possibility for HFBII to form rather strong and stable gel-like
Comment [VD2]: Figure 7 has been revised for uniformity, as requested by Reviewer 1.
Comment [VD3]: Figure 8 has been revised for uniformity, as requested by Reviewer 1. 
emulsions might be promising for future oil/water barrier applications, in order to stabilize the separation between oil and aqueous phases.

\section{ACKNOWLEDGEMENTS}

The authors thank Eni S.p.A. for funding and giving permission to publish these results. The authors also wish to thank Riitta Suihkonen (VTT, Finland) for protein expression and purification.

\section{REFERENCES}

1. L. W. Lake, R. Johns, B. Rossen, G. Pope. Fundamentals of Enhanced Oil Recovery, Society of Petroleum Engineers, Richardson (2014).

2. L. P. Dake. Fundamentals of Reservoir Engineering, Elsevier Science \& Technology, Oxford (1983).

3. A. Bera, A. Mandal. J. Petrol. Explor. Prod. Technol. 5, 255 (2015).

4. P. M. Mwangi, D. N. Rao. In Surfactant Science and Technology (L. S. Romsted, ed.), pp. 489-505. CRC Press, Boca Raton (2014).

5. G. G. Ying. Environ. Int. 32, 417 (2006).

6. S. De, S. Malik, A. Ghosh, R. Sahab, B. Saha. RSC Adv. 5, 65757 (2015).

7. D. G. DeAlmeida, R. de Cássia, F. Soares Da Silva, J. M. Luna, R. D. Rufino, V. A. Santos, I. M. Banat, L. A. Sarubbo. Frontiers Microbiol. 7, 1718 (2016).

8. C. N. Mulligan. Environmental Pollution 133, 183 (2005).

9. N. Kosaric. Pure Appl. Chem. 64, 1731 (1992).

10. I. M. Banat. Bioresource Technol. 51, 1 (1995).

11. M. B. Linder. Curr. Opin. Colloid Interface Sci. 14, 356 (2009).

12. H. A. B. Wösten, K. Scholtmeijer. Appl. Microbiol. Biotechnol. 99, 1587 (2015).

13. Q. Ren, A. H. Kwan, M. Sunde. Pept. Sci. 100, 601 (2013).

14. M. Khalesi, K. Gebruers, G. Derdelinckx. Protein J. 34, 243 (2015).

15. G. R. Szilvay, T. Nakari-Setälä, M. B. Linder. Biochemistry 45, 8590 (2006).

16. A. J. Green, K. A.Littlejohn, P. Hooley, P. W. Cox. Curr. Opin. Colloid Interface Sci. 18, 292 (2013).

17. L. M. Bimbo, M. Sarparanta, E. Mäkilä, T. Laaksonen, P. Laaksonen, J. Salonen, M. B. Linder, J. Hirvnen, A. J. Airaksinen, H. A. Santos. Nanoscale 4, 3184 (2012).

18. D. Maiolo, C. Pigliacelli, P. Sánchez Moreno, M. B. Violatto, L. Talamini, I. Tirotta, R. Piccirillo, M. Zucchetti, L. Morosi, R. Frapolli, G. Candiani, P. Bigini, P. Metrangolo, F. Baldelli Bombelli. ACS Nano 11, 9413 (2017).

19. L. Gazzera, R. Milani, L. Pirrie, M. Schmutz, C. Blanck, G. Resnati, P. Metrangolo, M. P. Krafft. Angew. Chem. Int. Ed. 55, 10263 (2016).

20. K. Scholtmeijer, J. Wessels, H. Wösten. Appl. Microbiol. Biotechnol. 56, 1 (2001).

21. S. O. Lumsdon, J. Green, B. Stieglitz. Colloids Surf. B 44, 172 (2005).

22. R. Milani, E. Monogioudi, M. Baldrighi, G. Cavallo, V. Arima, L. Marra, A. Zizzari, R. Rinaldi, M. Linder, G. Resnati, P. Metrangolo. Soft Matter 9, 6505 (2013).

23. A. Piscitelli, P. Cicatiello, A. M. Gravagnuolo, I. Sorrentino, C. Pezzella, P. Giardina. Biomolecules 7, 45 (2017).

24. M. Soikkeli, K. Kurppa, M. Kainlauri, S. Arpiainen, A. Paananen, D. Gunnarsson, J. J. Joensuu, Pa. Laaksonen, M. Prunnila, M. B. Linder, J. Ahopelto. ACS Appl. Mater. Interfaces 8, 8257 (2016).

25. L. Gazzera, C. Corti, L. Pirrie, A. Paananen, A. Monfredini, G. Cavallo, S. Bettini, G. Giancane, L. Valli, M. B. Linder, G. Resnati, R. Milani, P. Metrangolo. Adv. Mater. Interfaces 1500170 (2015).

26. J. Hakanpää, A. Paananen, S. Askolin, T. Nakari-Setälä, T. Parkkinen, M. Penttilä, M. B. Linder, J. Rouvinen. J. Biol. Chem. 279, 534 (2004).

27. J. Hakanpää, M. Linder, A. Popov, A. Schmidt, J. Rouvinen. Acta Crystallogr. Sect. D Biol. Crystallogr. 62 , 356 (2006).

28. N. A. Alexandrov, K. G. Marinova, T. D. Gurkov, K. D. Danov, P. A. Kralchevsky, S. D. Stoyanov, T. B. J. Blijdenstein, L. N. Arnaudov, E. G. Pelan, A. Lips. J. Colloid Interface Sci. 376, 296 (2012).

29. A. R. Cox, F. Cagnol, A. B. Russell, M. J. Izzard. Langmuir 23, 7995 (2007).

30. A. Bode, B. Bechtloff, U. Baus, J. Huff, M. Guzmann, J. R. Wuensch, M. Scholtissek. CA Patent 2642375, Filed 30 Oct 2008 , Issued 2 May 2009.

31. M. Guzmann, Y. Liu, U. Baus. WO Patent 2006/103253, Filed 29 March 2006, Issued 22 March 2007.

32. M. Linder, K. Selber, T. Nakari-Setälä, M. Qiao, M. R. Kula, M. Penttilä. Biomacromolecules 2, 511 (2001).

33. A. S. Abu-Ruwaida, I. M. Banat, S. Haditirto, A. Salem, M. Kadri. Acta Biotech. 11, 315 (1991).

34. A. Paananen, E. Vuorimaa, M. Torkkeli, M. Penttilä, M. Kauranen, O. Ikkala, H. Lemmetyinen, R. Serimaa, M. B. Linder. Biochemistry 42, 5253 (2003).

35. K. Kisko, M. Torkkeli, E. Vuorimaa, H. Lemmetyinen, O. H. Seeck, M. Linder, R. Serimaa. Surface Sci. 584, 35 (2005).

36. M. Zhou, R. D. Rhue, J. Colloid Interface Sci. 228, 18 (2000).

37. M. S.Grunér, A. Paananen, G. R.Szilvay, M. B.Linder, Colloids Surf. B 155, 111 (2017). 


\title{
Evaluating the potential of natural surfactants in the petroleum industry: The case of hydrophobins
}

\author{
Marijana Blesic, ${ }^{1}$ Valentina Dichiarante, ${ }^{1}$ Roberto Milani, ${ }^{2}$ Markus Linder $^{3}$ and Pierangelo \\ Metrangolo $\$ 1,2,3$
}

\begin{abstract}
Enhancing oil recovery from currently available reservoirs is a major issue for petroleum companies. Among the possible strategies towards this, chemical flooding through injection of surfactants into the wells seems to be particularly promising, thanks to their ability to reduce oil/water interfacial tension that promotes oil mobilization. Environmental concerns about the use of synthetic surfactants led to a growing interest in their replacement with surfactants of biological origin, such as lipopeptides and glycolipids produced by several microorganisms. Hydrophobins are small amphiphilic proteins produced by filamentous fungi with high surface activity and good emulsification properties, and may represent a novel sustainable tool for this purpose. We report here a thorough study of their stability and emulsifying performance towards a model hydrocarbon mixture, in conditions that mimic those of real oil reservoirs (high salinity and high temperature). Due to the moderate interfacial tension reduction induced in such conditions, the application of hydrophobins in enhanced oil recovery techniques does not appear feasible at the moment, at least in absence of cosurfactants. On the other hand, the obtained results showed the potential of hydrophobins in promoting the formation of a gel-like emulsion 'barrier' at the oil/water interface.
\end{abstract}

Keywords: Biosurfactant; Enhanced Oil Recovery (EOR); Hydrophobin; Emulsion.

\section{INTRODUCTION}

The last decades have shown a steady decrease in new oil fields discoveries. Moreover, current world oil reservoirs are mostly mature fields. In order to fulfill the energy demand in the next years, one of the major concerns for oil companies is thus to increase oil recovery from the available ageing resources.

Primary recovery, which is the first extraction step carried out without introducing other substances into the well, can recover only $12 \%$ to $15 \%$ of the oil. When the pressure inside the reservoir is no longer sufficient to expel the oil, water is usually injected to recover an additional $15 \%$ to $20 \%$ oil. This method is known as secondary oil recovery or water flooding. The remaining $60-70 \%$ of oil forms a discontinuous phase, with oil droplets trapped by capillary forces, which can be at least partially collected through a tertiary recovery process, known as Enhanced Oil Recovery (EOR). EOR techniques are classified in thermal processes, gas injection, and chemical flooding [1], [2].

As concerns the third strategy, viz. chemical flooding, injections of surfactants, polymers and alkali are generally used, especially in the case of sandstone reservoirs. Sometimes their combination is preferred to improve the recovery. Microemulsions (namely, transparent homogeneous mixtures of hydrocarbons and water with large amounts of surfactants), for example, proved to be an efficient tool in EOR techniques, thanks to their ability to reduce oil-water interfacial tension, thus leading to high extraction efficiency [3].

The use of surfactants seems a particularly promising chemical EOR approach to solve some of the most common needs of the petroleum industry, such as: (i) reduce the mixing of oil and water layers during the oil recovering from wells, through stabilization of oil-water separation; (ii) increase oil fluidity during transport through pipelines, by emulsification; (iii) facilitate the release of oil trapped in pores and/or adhered to surfaces in wells. Indeed, when an aqueous surfactant formulation is injected into a mature oil reservoir and contacts the small oil drops trapped in the pores of the reservoir rock, it reduces the interfacial tension and mobilizes the trapped oil by increasing the capillary number. Among all the available surfactants, anionic derivatives, e.g. sulfates and sulfonates, have been widely used for EOR purposes, in particular from sandstone rock matrices. Cationic amphiphiles have been rarely used, but they might be useful for oil extraction from positively charged carbonate rocks. Nonionic surfactants proved to be more tolerant towards high salinity than anionic ones, but are usually used as cosurfactants due to their lower ability to reduce interfacial activity [4].

Chemically synthesized surfactants are mainly petroleum-based, and have slow microbial degradation [5]. Therefore, they may bioaccumulate or give rise to environmentally hazardous by-products. Natural surfactants, also termed biosurfactants or microbial surface active agents, are amphiphilic compounds of biological origin produced by a variety of microorganisms -

\footnotetext{
1 Laboratory of Supramolecular and BioNano Materials (SupraBioNanoLab), Department of Chemistry, Materials, and Chemical Engineering "Giulio Natta", Politecnico di Milano, 20131 Milan, Italy; ${ }^{2}$ VTT-Technical Research Centre of Finland, 02150 Espoo, Finland; ${ }^{3}$ UNITWIN Network GREENOMIcS, Aalto University, 02150 Espoo, Finland.

${ }^{\ddagger}$ Corresponding author. E-mail: pierangelo.metrangolo@polimi.it
} 
including bacteria, yeasts, and fungi - from various substances and sometimes also from waste materials. They are usually classified into low molecular weight compounds (lipopeptides, glycolipids) and high molecular weight polymers [6]. Thanks to their unique properties, such as low toxicity, functionality under extreme conditions, biodegradable nature, and specific action, biosurfactants have several potential applications in the petroleum industry, mainly for the so-called Microbial Enhanced Oil Recovery (MEOR) [7], [8], [9]. Up to now, a major role in MEOR techniques was played by rhamnolipid, sophorolipid, glycolipid and lipopeptide biosurfactants [7]. Three main strategies can be adopted for using biosurfactants in EOR processes or mobilization of heavy oils: (i) direct injection of biosurfactant-producing microorganisms into the reservoir through the well, followed by their in situ multiplication through the reservoir rocks; (ii) ex situ injection of selected nutrients into a reservoir, to stimulate the growth of biosurfactant-producing microorganisms; (iii) external production of biosurfactants and their subsequent injection into the reservoir. Although glycolipids produced by Pseudomonas strains have been the most extensively used biosurfactants in MEOR experiments, lipopeptides - like surfactin and lichenysin - and lipid polysaccharide complexes were also found quite effective. Surfactin, a lipopeptide considered the most potent microbial surfactant known so far, was produced ex situ in a fermenter under controlled conditions and successfully used in MEOR [10].

Recently, a family of small Cysteine-rich amphiphilic proteins, called hydrophobins (HFBs), raised huge interest as novel biosurfactants and surface coating agents. HFBs are naturally produced in filamentous fungi and usually comprise about 100 amino acids, with molecular weights in the range of 7-15 kDa [11], [12], [13], [14]. According to the different clustering of hydrophobic and hydrophilic residues, they are grouped into Class I and Class II hydrophobins. At concentrations of few $\mu \mathrm{g} / \mathrm{mL}$, both classes of hydrophobins exist as monomers. At higher concentrations they form dimers. In a concentration range of $0.5-10 \mathrm{mg} / \mathrm{mL}$, tetramers or larger aggregates are formed [15]. At interfaces, Class II HFBs form monolayers with a significant degree of elasticity, whereas Class I proteins form multilayers. The good surface activity and exceptionally high surface elasticity of HFBs makes them the most surface-active proteins currently known, which promoted their successful exploitation in several different fields. Some of the uses proposed for HFBs include stabilization of foams and emulsions in the food industry [16], biotechnological applications such as drug delivery [17], [18], biomedical imaging [19] and coatings for biomedical devices [20], but also use as dispersing agents [21], [22] and intermediates for surface immobilization of proteins [23], [24] and polymers [25]. The ability of HFBs to self-assemble at oil-water interfaces and stabilize oil droplets makes them potential candidates for a more efficient and greener EOR strategy, also in consideration of the fact that the potential for large scale production of these proteins has been shown in industrial operations for both classes of HFBs [14], [16].

The present work focuses on HFBII, a Class II hydrophobin produced by Trichoderma reesei. Its reported crystal structure shows a nearly globular shape with a central $\beta$-barrel structure, a small segment of $\alpha$-helix, and an extended network of disulfide bonds stabilizing the structure [26], [27]. The protein surface is mainly hydrophilic, except for a flat 'hydrophobic patch' formed by two hairpin loops containing several aliphatic side chains. Such portion covers about $12 \%$ of HFBII total surface accessible area and is responsible of its amphiphilic behavior. HFBII has a molecular weight of about $7.2 \mathrm{kDa}$ and an isoelectric point between 6 and 7 [28]. This relatively small protein (less than $3 \mathrm{~nm}$ diameter) can lower the air/water surface tension to $35 \mathrm{mN} / \mathrm{m}$ at a concentration of $30 \mu \mathrm{M}[29]$.

To the best of our knowledge, the behaviour of HFBII in conditions relevant to petroleum industry applications has not been studied in depth, yet, and only a few patents were published on the subject. Patent CA 2642375, for example, describes a process for extracting hydrocarbons from oil sand with water and a hydrophobin [30]. Different $\mathrm{pH}$ and temperatures were screened, and a three-phase system was obtained in all cases. Hydrocarbons were found in all the phases (upper foam, aqueous middle and lower solid phases), although addition of hydrophobin increased the yield of hydrocarbons in the foam phase. Another patent (WO 2006/103253) claims the use of hydrophobins as auxiliary-emulsifying agents for a drilling fluid [31]. The reported drilling mud contained from 40 to $95 \%$ by weight of at least one oil component, from 2 to $60 \%$ by weight of water, and other components.

We report herein an exploratory study, aimed to establish whether HFBII holds promise as an additive in the petroleum industry, taking into consideration, for example, the influence exerted by seawater salinity or high temperatures on its emulsifying properties. We focused, in particular, on the following aspects: (i) possible formation of HFBII stable films at the water/oil interface, to create a barrier between the two phases; (ii) its performance as emulsifying agent, to disperse oil in water and increase its fluidity; (iii) the potential of this protein for Enhanced Oil Recovery.

\section{MATERIALS AND EXPERIMENTAL}

HFBII was obtained from T. reesei QM 9414 strain with a purity grade of about $98 \%$ (without HPLC purification) [32]. Synthetic seawater (SSW) was prepared by dissolving $24.53 \mathrm{~g}$ of NaCl, $4.09 \mathrm{~g}$ of $\mathrm{Na}_{2} \mathrm{SO}_{4}, 0.695 \mathrm{~g}$ of $\mathrm{KCl}, 1.16 \mathrm{~g}$ of $\mathrm{CaCl}_{2}$ and $5.20 \mathrm{~g}$ of $\mathrm{MgCl}_{2} \cdot 6 \mathrm{H}_{2} \mathrm{O}$ in $1 \mathrm{~L}$ of Milli-Q water (approximate salinity: $35 \mathrm{~g} / \mathrm{L}$ ). A high salinity water solution (approximate salinity: $70 \mathrm{~g} / \mathrm{L}$ ) was also prepared, doubling all salts concentrations. Dectol was prepared by mixing decane and toluene in 
65:35 volume ratio, and used as a 'model oil'. Emulsions were obtained by manual mixing, in order to mimic real mixing conditions. For rheology measurements and droplet size determination only, a high speed stator-rotor homogenizer (Heidolph DIAX 900) was used to provide better reproducibility.

For "Double Titration" experiments, five hydrophobin solutions in Milli-Q water with different concentrations of the protein $(5,7.5,10,15$ and $20 \mathrm{mg} / \mathrm{mL})$ were prepared. Titrations were done adding progressively small portions of the high salinity solution to hydrophobin solutions, until flocculation or precipitation occurred.

Tensiometric measurements at the SSW/dectol interface (pendant drop method) were performed on a CAM 200 (KSV Instruments Ltd.) and operated with the software CAM 2008 supplied with the instrument. Three different HFBII concentrations $(1,0.1$ and $0.01 \mathrm{mg} / \mathrm{mL})$ were tested.

Emulsion 'bulk' rheology was measured with an AR G2 rheometer with parallel plate geometry (TA Instruments Ltd). Interfacial shear rheology was measured using a Du Noüy ring (1.2 cm diameter) oscillating in plane. Du Noüy ring connected to AR-G2 rheometer is commonly used for sensitive interfacial measurements, because of its low inertia and its capability to control and apply tiny torques. The Du Noüy ring was attached to the stress motor, mounted on the slide of the rheometer. A circular glass dish was located in the centre of the Peltier plate. Viscoelasticity of the selected emulsions was characterized by measuring their storage modulus (G') and loss modulus (G') in the linear viscoelastic region, keeping the frequency constant at $0.1 \mathrm{~Hz}$. Samples with 50:50 w/o ratio and different HFBII concentrations were analysed $48 \mathrm{~h}$ after emulsification.

The emulsification index $\mathrm{E}_{24}$ was determined according to a reported procedure [33]. In a typical experiment, dectol (6 $\mathrm{mL}$ ) was added to the biosurfactant solution $(4 \mathrm{~mL})$ in a graduated tube, vortexed at high speed for 2 minutes, and then left standing for $24 \mathrm{~h}$. The emulsification index was calculated dividing the final height of the emulsion layer by the total height, and multiplying by 100 .

Microscopy analyses were performed on an Olympus BX40 optical microscope (Olympus, Center Valley, Pennsylvania, USA) and a Zeiss LSM 710 microscope with a He/Ne laser $\left(\lambda_{\mathrm{ex}}=543 \mathrm{~nm}\right)$ using contrast phase, bright field and confocal microscopy techniques. Droplet size determination was calculated from the optical microscopy images from an average of ca. 2000 droplets. In confocal microscopy images specific dyes were used to stain oil and protein, namely Nile Red for oil phase and fluorescein isothiocyanate for HFBII.

\section{RESULTS AND DISCUSSION}

\section{Preliminary stability studies}

First, the stability of HFBII in SSW was evaluated by means of flocculation studies, varying different parameters. Double titration experiments were carried out at room temperature $\left(20^{\circ} \mathrm{C}\right)$ to establish the relationship between HFBII stability and salt concentration. After the addition of a certain volume of SSW to HFBII solutions, flocculation or precipitation of the protein occurred for all selected concentrations. In this process, the following behaviour was observed: i) appearance of a strong opalescence, ii) appearance of flakes in solution, iii) precipitation of a white solid. In Figure 1a, the final point of each series represents its 'flocculation point'. The curve connecting such points gives an indication of the protein stability and solubility at different salinity levels. Salinity actually affects the protein solubility in aqueous media, but not to a point as to prevent its use.

A similar set of experiments was performed at 40 and $70{ }^{\circ} \mathrm{C}$, to test the influence of temperature on HFBII stability in SSW. As shown in Figure 1b, the protein behaviour did not change at $40{ }^{\circ} \mathrm{C}$, whereas at $70{ }^{\circ} \mathrm{C}$ a significant solubility increase was observed.

It should be noticed that HFBII flocculation is a slow kinetic process. The reported flocculation points refer to short times, but precipitation can occur even at lower protein concentration or salinities, if enough time is given, particularly under the effect of shear forces. 

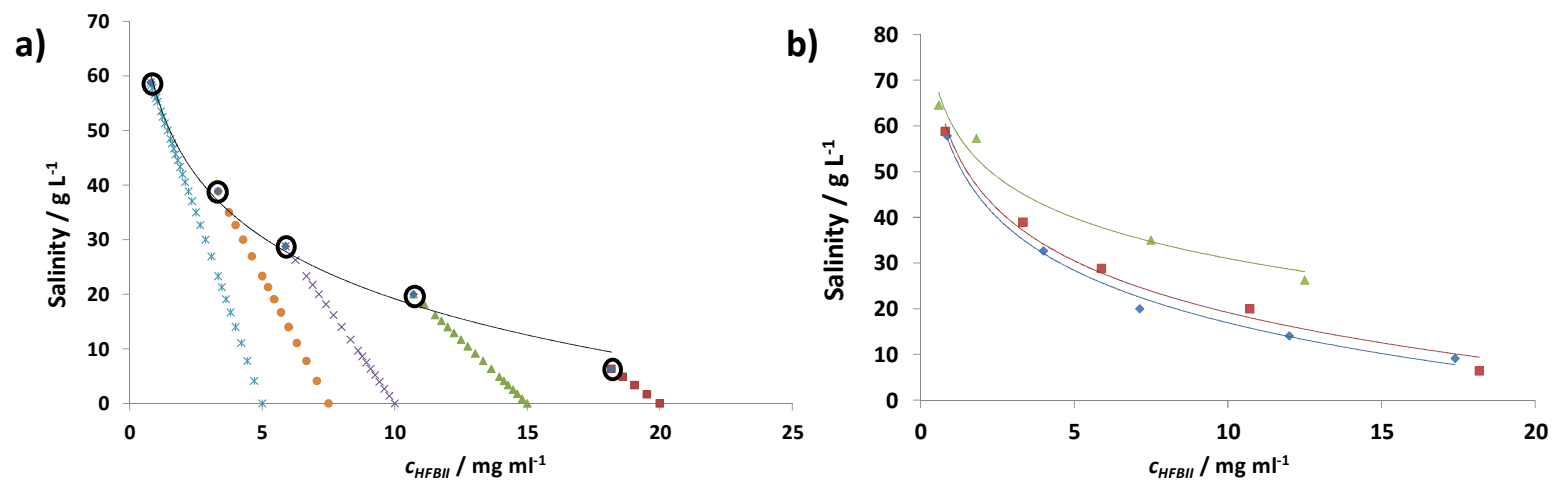

Fig. 1. a) Titration curves, showing salinity values versus different HFBII concentrations: $5(*), 7.5(\bullet), 10(\times), 15(\Delta)$, and 20 $\mathrm{mg} / \mathrm{mL}(\square)$. Flocculation points for each series are marked with a black circle. b) Flocculation points obtained at different temperatures, varying HFBII concentration: $20^{\circ} \mathrm{C}(\boldsymbol{\square}), 40^{\circ} \mathrm{C}(\diamond)$, and $70{ }^{\circ} \mathrm{C}(\Delta)$.

\section{Film formation}

To verify if HFBII still forms films in SSW as it does in low salinity aqueous media [34], [35], and how strong these films are, we measured first the interfacial tension reduction at the SSW/dectol interface through pendant drop measurements. The results confirmed that the protein works in SSW as it does in low salinity water. Compared to the value measured for SSW (about 37 $\mathrm{mN} / \mathrm{m}$ ), both $1 \mathrm{mg} / \mathrm{mL}$ and $0.1 \mathrm{mg} / \mathrm{mL}$ HFBII concentrations in SSW are able to reduce the surface tension until $15-16 \mathrm{mN} / \mathrm{m}$ (Figure 2). Reduction occurred instantly, although the interfacial tension kept on decreasing very slowly over time. This is consistent with the typical mechanism of HFB self-assembly, which involves first fast protein adsorption at the oil/water interface, followed by slow structural rearrangement of the adsorbed hydrophobin layer into closer packing [34].

Unfortunately the reduction of interface tension obtained with HFBII does not lead to the ultralow values typically needed in EOR applications $(<1 \mathrm{mN} / \mathrm{m})$, indicating that HFBII holds little promise in this sense, at least in the absence of a suitable co-surfactant. The addition of medium chain alcohols such as propan-2-ol, butanol or isoamyl alcohol, for example, has been shown to facilitate the preparation of microemulsions suitable for EOR [3], [36].

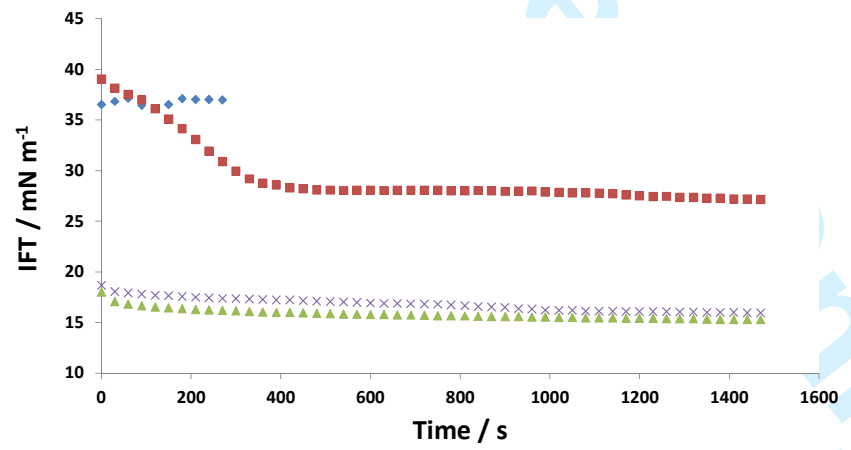

Fig. 2. Interfacial tension trends over time for SSW solutions of HFBII at different protein concentrations: $0(\diamond), 0.01(\boldsymbol{\bullet}), 0.1(\Delta)$, and $1 \mathrm{mg} / \mathrm{mL}(\times)$.

Interfacial shear rheology measurements (Figure 3) showed that the film formed at the SSW/dectol interface is remarkably strong and elastic. Salinity did not seem to affect the film strength, which was comparable to that observed at water/oil and water/air interfaces. This can be promising for barrier applications. 
a)

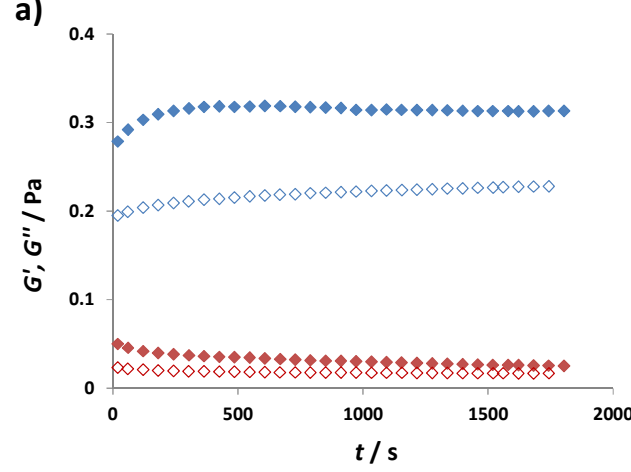

b)

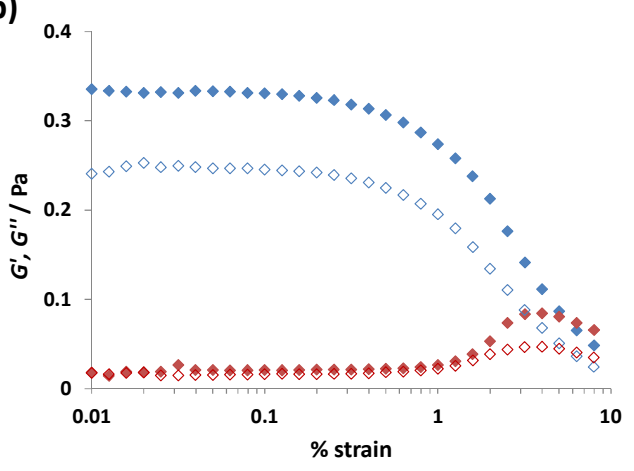

Fig. 3. Air-SSW (solid diamonds) and Dectol-SSW (empty diamonds) interfacial shear moduli G' (blue series) and G' (red series), measured at $0.05 \mathrm{mg} / \mathrm{mL}$ HFBII concentration and $0.1 \mathrm{~Hz}$ frequency, as a function of: a) time (with $0.5 \%$ strain); b) strain.

\section{Emulsification studies}

A systematic study of the emulsification of the SSW/dectol mixture in the presence of HFBII was performed, to verify the impact of several relevant parameters on the emulsification ability of the protein. The rheological properties of these emulsions were also studied, since a thick, resistant emulsion layer could favour the separation between oil and water.

First, the emulsification index $\mathrm{E}_{24}$ of HFBII in Milli-Q/dectol systems was measured, and compared to those of several ionic and non-ionic commercially available surfactants. HFBII performed well, showing an emulsification index in line with those observed for some of the best performing emulsifiers, such as Brij 58 and Didecyl-Dimethyl-Ammonium Chloride (Table 1).

Table 1

\begin{tabular}{lll}
\hline Surfactant & Class & $\mathbf{E}_{24}$ \\
\hline HFBII & Protein & 74 \\
Didecyl-Dimethyl-Ammonium Chloride & Cationic & 81 \\
Sodium Dodecyl Sulfate & Anionic & 34 \\
Brij 58 & Nonionic & 78 \\
Triton X-100 & Nonionic & 21 \\
Tween 80 & Nonionic & 10 \\
Tergitol NP-9 & Nonionic & 3 \\
Span 85 & Nonionic & 0 \\
\hline
\end{tabular}

To clarify the influence of salinity on HFBII/oil emulsions, two samples were prepared dissolving the same amount of HFBII in SSW and Milli-Q water, respectively, with a 50:50 o/w ratio. As shown in Figure 4, both visual inspection and contrast phase microscopy confirmed the presence of significant differences in emulsion structure and thickness, as well as in oil droplets distribution. The emulsion layer of dectol in SSW was clearly less thick than that prepared in Milli-Q water, and displayed droplets with smaller maximum size and reduced size variability. Although high salinity reduced the emulsifying power of hydrophobin, the protein was still able to form emulsions. 

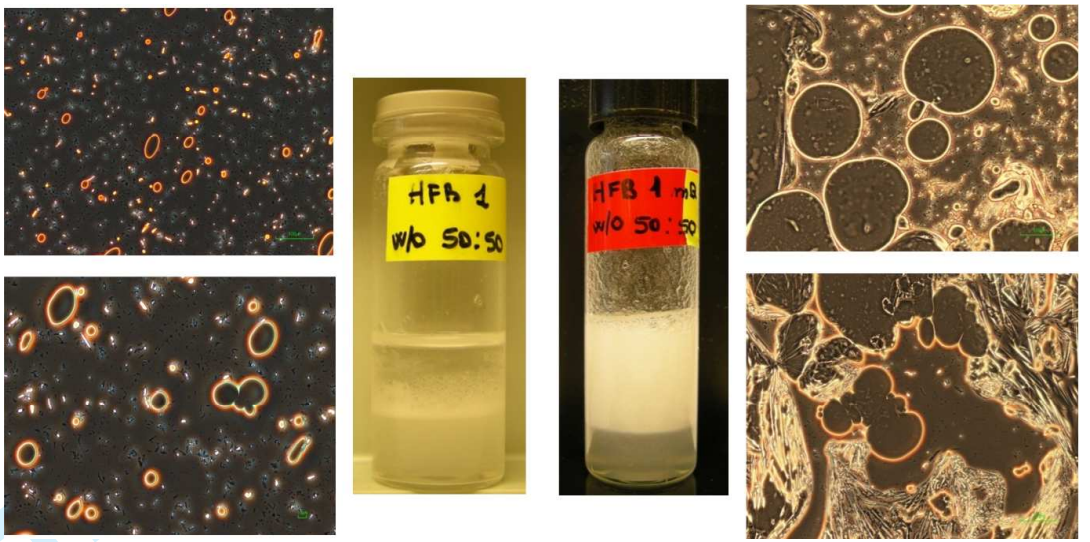

Fig. 4. Pictures and contrast phase microscopy images of 50:50 o/w emulsions obtained from $1 \mathrm{mg} / \mathrm{mL}$ HFBII solutions in SSW (left) and Milli-Q water (right).

The effect of temperature on emulsion stability was evaluated using the following procedure: a 50:50 mixture of dectol and 1 $\mathrm{mg} / \mathrm{mL}$ aqueous solution of HFBII was homogenized for 3 minutes, then kept at different temperatures $\left(20^{\circ} \mathrm{C}, 40{ }^{\circ} \mathrm{C}\right.$ and 70 ${ }^{\circ} \mathrm{C}$ ) for $2.5 \mathrm{~h}$ in a thermostatic bath, and centrifuged. Microscopy analyses showed no significant changes in the mean volumesurface radius $\left(\mathrm{R}_{32}\right)$ or relative height of the emulsion phase (Figure 5), meaning that thermal treatment of the emulsions did not affect the protein emulsifying properties.

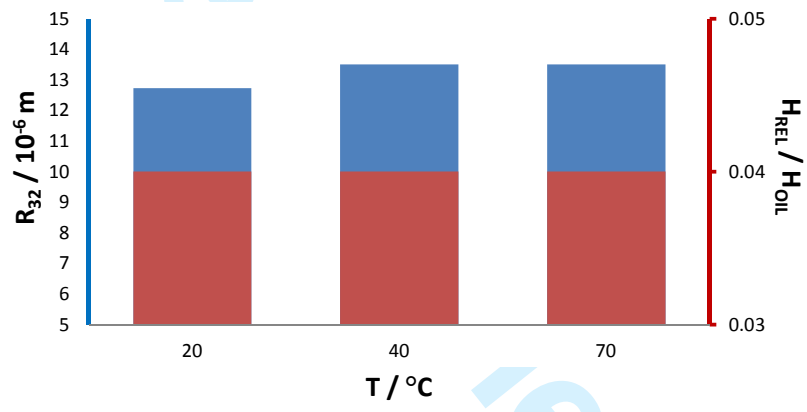

Fig. 5. Effect of thermal treatment at different temperatures on mean volume-surface radius $\left(\mathrm{R}_{32}\right.$, blue $)$ and relative volume of oil released from emulsions after centrifugation $\left(\mathrm{H}_{\mathrm{REL}} / \mathrm{H}_{\mathrm{OIL}}\right.$, red).

Further experiments were carried out to assess the effect of HFBII concentration and water/oil ratio. A set of five different HFBII concentrations $(0.1,0.25,0.5,0.75$, and $1 \mathrm{mg} / \mathrm{mL})$ in SSW were mixed with dectol in five different w/o ratios $(1: 9,3: 7$, $1: 1,7: 3,9: 1)$ for 2 minutes with a high speed homogenizer. After $24 \mathrm{~h}$ resting, we measured the volumes of the obtained layers.

For a constant w/o ratio the curves of the relative emulsified volume $\mathrm{V}_{\mathrm{em}} / \mathrm{V}_{\mathrm{oil}}$ vs. HFBII concentration showed a trend of slight increase at lower surfactant concentrations, i.e., in the region between the $\mathrm{y}$ axis and the green line. This indicates that HFBII concentrations of about $0.5 \mathrm{mg} / \mathrm{mL}$ (effective concentration on total mixture volume) are necessary to reach a maximum in the relative emulsified volume (Figure 6a), and that further addition of protein would not lead to any significant increase. Bright field optical microscopy images revealed that below $0.5 \mathrm{mg} / \mathrm{mL}$ HFBII concentration, emulsions with a uniform size distribution cannot be obtained (Figure 6b). Above this threshold value the average droplet size can be controlled by varying the protein concentration, as shown by the analysis of the mean volume-surface ratio $\mathrm{R}_{32}$ of the oil droplets (Figure $6 \mathrm{c}$ ), and the emulsions were relatively monodisperse (Figure 6d).

The results also indicated that w/o ratios $\geq 0.5$ are necessary to obtain a two-phase regime rather than three phases (Figure 6a). The two-phase system is not a typical Winsor type II system. While there is indeed an upper emulsion phase and a lower aqueous phase, the emulsion is however of the oil-in-water type rather than water-in-oil, and it is actually a miniemulsion rather than a microemulsion [4]. Indeed by staining the protein with fluorescein isothiocyanate and the oil phase with Nile Red, it was possible to see in confocal microscopy images that the samples are consistently oil-in-water emulsions, and that HFBII is present both in the bulk aqueous solution and as films connecting the oil droplets, which, however, do not coalesce (Figure $6 e)$. 


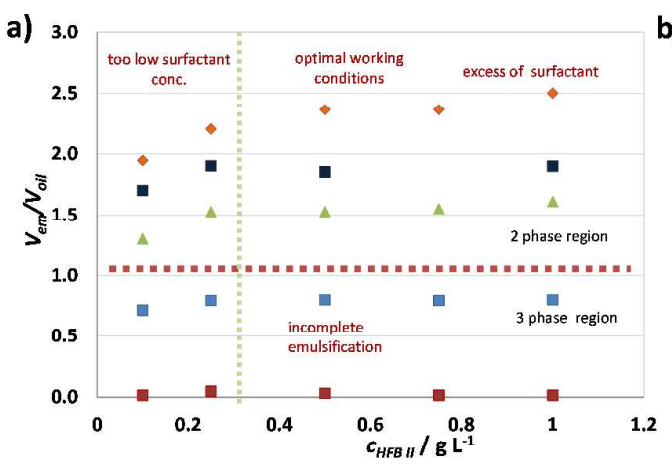

b)

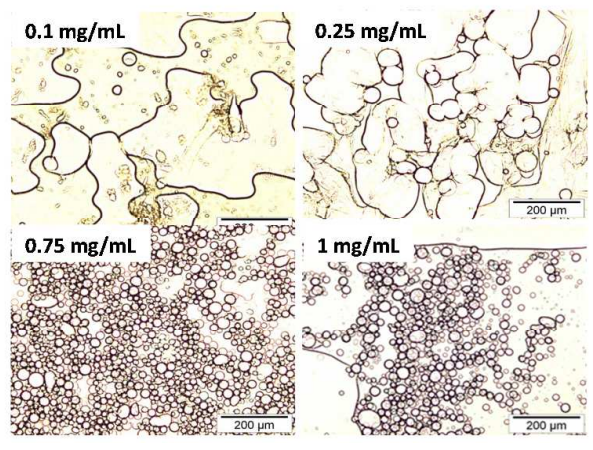

c)

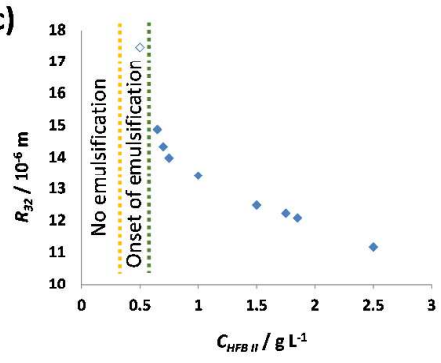

d)

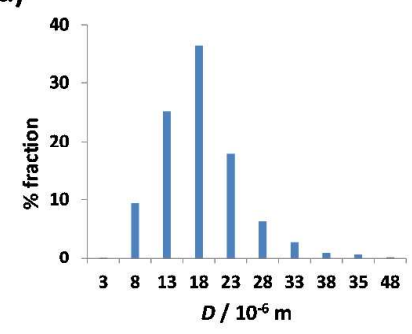

e)

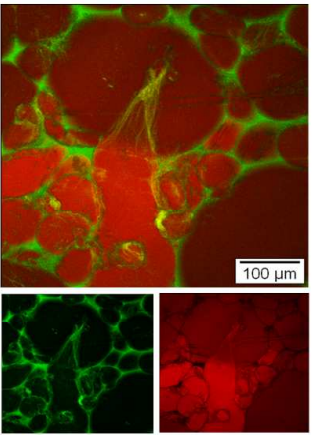

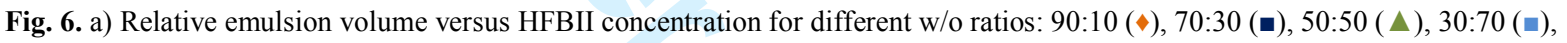
10:90 (घ). b) Bright field microscopy images of 1:1 w/o mixtures with increasing HFBII concentrations. c) Mean volume-surface radius as a function of hydrophobin concentration. d) Average droplet size distribution for $1 \mathrm{mg} / \mathrm{mL}$ HFBII concentration. e) Confocal microscopy images of 4:1 w/o emulsions with $1 \mathrm{mg} / \mathrm{mL}$ HFBII (green staining: protein; red staining: oil phase).

We studied the rheology of bulk emulsions at three different concentrations of HFBII, with a constant 1:1 w/o ratio and after a $48 \mathrm{~h}$ resting time (Figure 7a). For HFBII concentrations of 0.5 and $1 \mathrm{mg} / \mathrm{mL}$ the emulsions behave like gels (G' >> G'), with higher strength compared to other surfactants such as Brij and sodium dodecyl sulfate (SDS, Figure 7b). The significantly higher values obtained for the storage modulus G', compared to the loss modulus G', revealed that such emulsions had predominantly elastic (solid-like) behaviour. A minimum concentration of $0.5 \mathrm{mg} / \mathrm{mL}$ hydrophobin was needed to have relatively strong emulsion layers, as confirmed by the much lower G' value found for $0.25 \mathrm{mg} / \mathrm{mL}$ HFBII concentration, which only formed a weak gel, and in agreement with the results of the emulsification studies exposed above. This gel-like behaviour of hydrophobin emulsions is not promising for EOR applications or for oil fluidification through emulsification, but could be useful for the formation of an oil/water barrier. However, it should be noted that also in this case the use of a co-surfactant like a short or medium-chain alcohol might lead to a reduction of the tendency to form rigid structures, as previously shown for microemulsions targeted at EOR [3]. In addition, previous literature demonstrated that alcohols can affect the assembly of hydrophobins by stabilizing their monomeric form over the formation of aggregates [37], which might indeed lead to less rigid protein films. 
a)

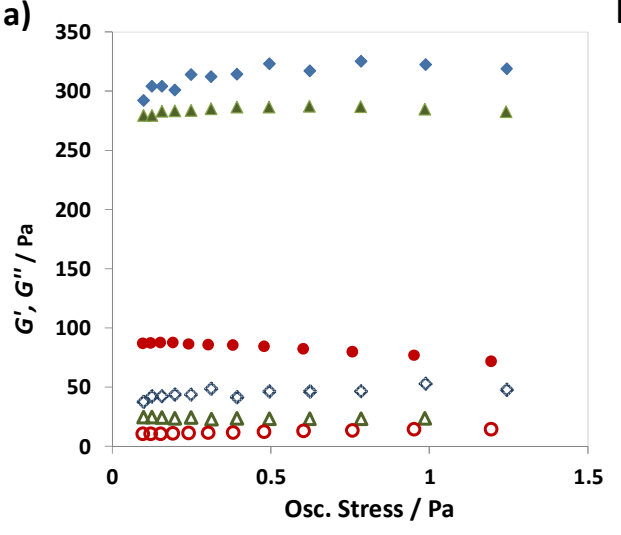

b)

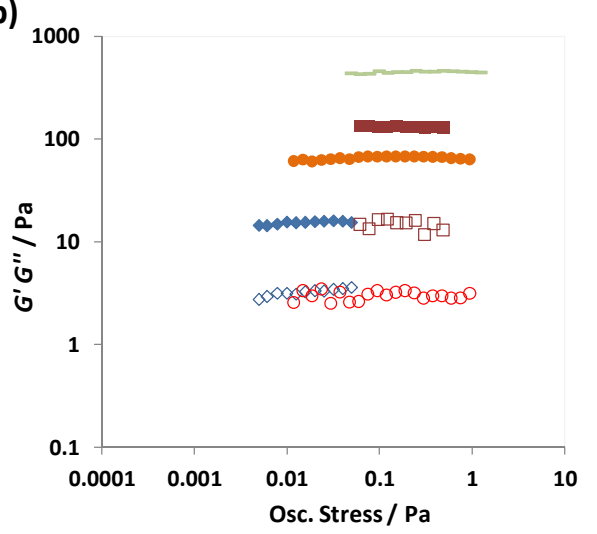

Fig. 7. Stress dependence of emulsion storage (G', solid symbols) and loss modulus (G', empty symbols) in the near viscoelastic region: a) comparison among different HFBII concentrations: $0.25(\bullet), 0.5(\Delta)$, and $1 \mathrm{mg} / \mathrm{mL}(\diamond)$; b) comparison among different surfactants: Brij $1 \mathrm{mg} / \mathrm{mL}(\diamond), \operatorname{SDS} 2 \mathrm{mg} / \mathrm{mL}(\bullet), \operatorname{SDS} 3 \mathrm{mg} / \mathrm{mL}(\bullet)$, and HFBII $2.5 \mathrm{mg} / \mathrm{mL}(-)$.

These and previous results are summarized in the phase diagram shown in Figure 8, which illustrates the different behaviour regimes for SSW/dectol emulsions (Figure 8). For very low water content $(\mathrm{w} / \mathrm{o}=1: 9)$, stable emulsions cannot be formed. At slightly higher water content $(w / o=3: 7)$ three layers were detected: aqueous phase, emulsion and oil phase. This region (below the red line in Figure 6a) represents a regime of incomplete emulsification. For even higher water content the presence of only two phases was found (above the red line in Figure 6a), thus indicating complete oil emulsification. Here the volume of the emulsion layer is higher than the volume of the starting oil layer, and a higher water content results in higher relative volume of the emulsion layer. At these higher w/o ratios the rheological properties of the obtained emulsions depend essentially on HFBII concentration, behaving as weak emulsions roughly below $0.5 \mathrm{mg} / \mathrm{mL}$, and more like strong gels above this concentration.

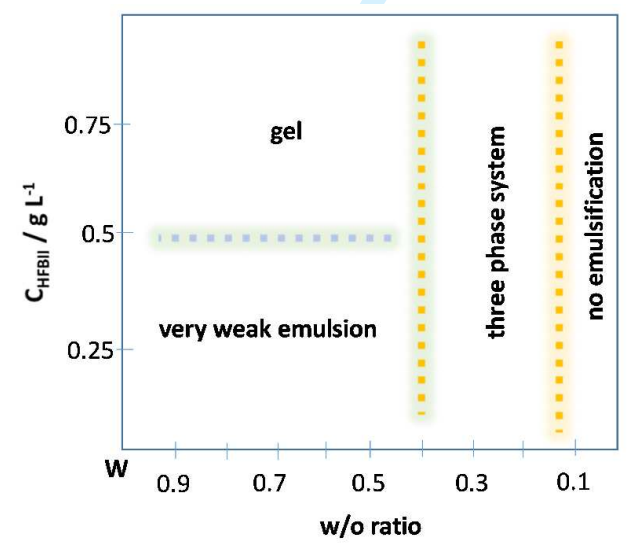

Fig. 8. Phase behaviour diagram of the studied emulsions, as a function of protein concentration $\left(\mathrm{C}_{\mathrm{HFB}}\right)$ and w/o ratio.

\section{CONCLUSIONS}

Even though the high salinity and temperature conditions typical of oil recovery might be detrimental to its performance as a surfactant, the hydrophobin HFBII proved to still be able to form films and relatively strong emulsions in SSW up to $70{ }^{\circ} \mathrm{C}$, and its emulsifying power compared favourably to other surfactants. In spite of this, HFBII did not seem particularly promising for EOR and oil fluidification through emulsification, due to insufficient interface tension reduction and to the tendency to form gel-like miniemulsions. It is, however, worth noticing that the choice of an appropriate co-surfactant (e.g. medium chain alcohols) may improve HFBII performance in terms of EOR, both by facilitating microemulsion formation and by reducing the tendency to form a rigid gel-like structure. Furthermore, the possibility for HFBII to form rather strong and stable gel-like 
emulsions might be promising for future oil/water barrier applications, in order to stabilize the separation between oil and aqueous phases.

\section{ACKNOWLEDGEMENTS}

The authors thank Eni S.p.A. for funding and giving permission to publish these results. The authors also wish to thank Riitta Suihkonen (VTT, Finland) for protein expression and purification.

\section{REFERENCES}

1. L. W. Lake, R. Johns, B. Rossen, G. Pope. Fundamentals of Enhanced Oil Recovery, Society of Petroleum Engineers, Richardson (2014).

2. L. P. Dake. Fundamentals of Reservoir Engineering, Elsevier Science \& Technology, Oxford (1983).

3. A. Bera, A. Mandal. J. Petrol. Explor. Prod. Technol. 5, 255 (2015).

4. P. M. Mwangi, D. N. Rao. In Surfactant Science and Technology (L. S. Romsted, ed.), pp. 489-505. CRC Press, Boca Raton (2014).

5. G. G. Ying. Environ. Int. 32, 417 (2006).

6. S. De, S. Malik, A. Ghosh, R. Sahab, B. Saha. RSC Adv. 5, 65757 (2015).

7. D. G. DeAlmeida, R. de Cássia, F. Soares Da Silva, J. M. Luna, R. D. Rufino, V. A. Santos, I. M. Banat, L. A. Sarubbo. Frontiers Microbiol. 7, 1718 (2016).

8. C. N. Mulligan. Environmental Pollution 133, 183 (2005).

9. N. Kosaric. Pure Appl. Chem. 64, 1731 (1992).

10. I. M. Banat. Bioresource Technol. 51, 1 (1995).

11. M. B. Linder. Curr. Opin. Colloid Interface Sci. 14, 356 (2009).

12. H. A. B. Wösten, K. Scholtmeijer. Appl. Microbiol. Biotechnol. 99, 1587 (2015).

13. Q. Ren, A. H. Kwan, M. Sunde. Pept. Sci. 100, 601 (2013).

14. M. Khalesi, K. Gebruers, G. Derdelinckx. Protein J. 34, 243 (2015).

15. G. R. Szilvay, T. Nakari-Setälä, M. B. Linder. Biochemistry 45, 8590 (2006).

16. A. J. Green, K. A.Littlejohn, P. Hooley, P. W. Cox. Curr. Opin. Colloid Interface Sci. 18, 292 (2013).

17. L. M. Bimbo, M. Sarparanta, E. Mäkilä, T. Laaksonen, P. Laaksonen, J. Salonen, M. B. Linder, J. Hirvnen, A. J. Airaksinen, H. A. Santos. Nanoscale 4, 3184 (2012).

18. D. Maiolo, C. Pigliacelli, P. Sánchez Moreno, M. B. Violatto, L. Talamini, I. Tirotta, R. Piccirillo, M. Zucchetti, L. Morosi, R. Frapolli, G. Candiani, P. Bigini, P. Metrangolo, F. Baldelli Bombelli. ACS Nano 11, 9413 (2017).

19. L. Gazzera, R. Milani, L. Pirrie, M. Schmutz, C. Blanck, G. Resnati, P. Metrangolo, M. P. Krafft. Angew. Chem. Int. Ed. 55, 10263 (2016).

20. K. Scholtmeijer, J. Wessels, H. Wösten. Appl. Microbiol. Biotechnol. 56, 1 (2001).

21. S. O. Lumsdon, J. Green, B. Stieglitz. Colloids Surf. B 44, 172 (2005).

22. R. Milani, E. Monogioudi, M. Baldrighi, G. Cavallo, V. Arima, L. Marra, A. Zizzari, R. Rinaldi, M. Linder, G. Resnati, P. Metrangolo. Soft Matter 9, 6505 (2013).

23. A. Piscitelli, P. Cicatiello, A. M. Gravagnuolo, I. Sorrentino, C. Pezzella, P. Giardina. Biomolecules 7, 45 (2017).

24. M. Soikkeli, K. Kurppa, M. Kainlauri, S. Arpiainen, A. Paananen, D. Gunnarsson, J. J. Joensuu, Pa. Laaksonen, M. Prunnila, M. B. Linder, J. Ahopelto. ACS Appl. Mater. Interfaces 8, 8257 (2016).

25. L. Gazzera, C. Corti, L. Pirrie, A. Paananen, A. Monfredini, G. Cavallo, S. Bettini, G. Giancane, L. Valli, M. B. Linder, G. Resnati, R. Milani, P. Metrangolo. Adv. Mater. Interfaces 1500170 (2015).

26. J. Hakanpää, A. Paananen, S. Askolin, T. Nakari-Setälä, T. Parkkinen, M. Penttilä, M. B. Linder, J. Rouvinen. J. Biol. Chem. 279, 534 (2004).

27. J. Hakanpää, M. Linder, A. Popov, A. Schmidt, J. Rouvinen. Acta Crystallogr. Sect. D Biol. Crystallogr. 62, 356 (2006).

28. N. A. Alexandrov, K. G. Marinova, T. D. Gurkov, K. D. Danov, P. A. Kralchevsky, S. D. Stoyanov, T. B. J. Blijdenstein, L. N. Arnaudov, E. G. Pelan, A. Lips. J. Colloid Interface Sci. 376, 296 (2012).

29. A. R. Cox, F. Cagnol, A. B. Russell, M. J. Izzard. Langmuir 23, 7995 (2007).

30. A. Bode, B. Bechtloff, U. Baus, J. Huff, M. Guzmann, J. R. Wuensch, M. Scholtissek. CA Patent 2642375, Filed 30 Oct 2008 , Issued 2 May 2009.

31. M. Guzmann, Y. Liu, U. Baus. WO Patent 2006/103253, Filed 29 March 2006, Issued 22 March 2007.

32. M. Linder, K. Selber, T. Nakari-Setälä, M. Qiao, M. R. Kula, M. Penttilä. Biomacromolecules 2, 511 (2001).

33. A. S. Abu-Ruwaida, I. M. Banat, S. Haditirto, A. Salem, M. Kadri. Acta Biotech. 11, 315 (1991).

34. A. Paananen, E. Vuorimaa, M. Torkkeli, M. Penttilä, M. Kauranen, O. Ikkala, H. Lemmetyinen, R. Serimaa, M. B. Linder. Biochemistry 42, 5253 (2003).

35. K. Kisko, M. Torkkeli, E. Vuorimaa, H. Lemmetyinen, O. H. Seeck, M. Linder, R. Serimaa. Surface Sci. 584, 35 (2005).

36. M. Zhou, R. D. Rhue, J. Colloid Interface Sci. 228, 18 (2000).

37. M. S.Grunér, A. Paananen, G. R.Szilvay, M. B.Linder, Colloids Surf. B 155, 111 (2017). 
Fig. 1. a) Titration curves, showing salinity values versus different HFBII concentrations: $5(v), 7.5(\bullet), 10$ $(\times), 15(\mathbf{\Lambda})$, and $20 \mathrm{mg} / \mathrm{mL}(\mathbf{-})$. Flocculation points for each series are marked with a black circle. b) Flocculation points obtained at different temperatures, varying HFBII concentration: $20^{\circ} \mathrm{C}(\mathbf{m}), 40^{\circ} \mathrm{C}(\bullet)$, and $70^{\circ} \mathrm{C}(\mathbf{\Lambda})$.

$183 \times 73 \mathrm{~mm}(150 \times 150 \mathrm{DPI})$ 
Fig. 2. Interfacial tension trends over time for SSW solutions of HFBII at different protein concentrations: 0 $(\bullet), 0.01(\mathbf{\bullet}), 0.1(\boldsymbol{\Delta})$, and $1 \mathrm{mg} / \mathrm{mL}(\times)$. $189 \times 105 \mathrm{~mm}(150 \times 150 \mathrm{DPI})$ 
Fig. 3. Air-SSW (solid diamonds) and Dectol-SSW (empty diamonds) interfacial shear moduli G' (blue series) and $\mathrm{G}^{\prime \prime}$ (red series), measured at $0.05 \mathrm{mg} / \mathrm{mL}$ HFBII concentration and $0.1 \mathrm{~Hz}$ frequency, as a function of: 

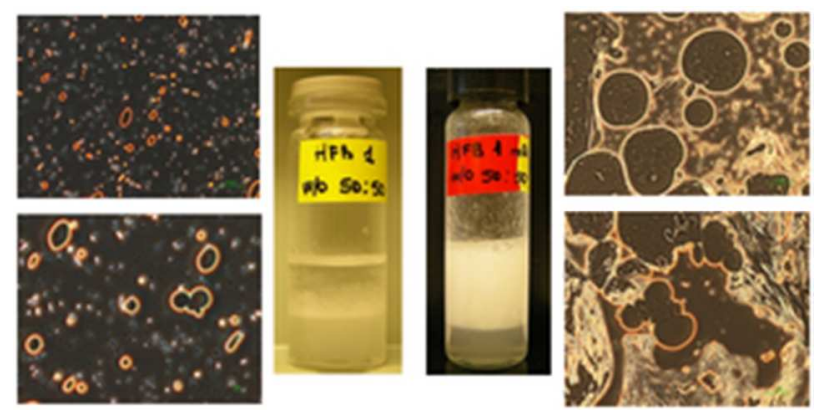

Fig. 4. Pictures and contrast phase microscopy images of 50:50 o/w emulsions obtained from $1 \mathrm{mg} / \mathrm{mL}$ HFBII solutions in SSW (left) and Milli-Q water (right).

$25 \times 13 \mathrm{~mm}(300 \times 300 \mathrm{DPI})$ 
Fig. 5. Effect of thermal treatment at different temperatures on mean volume-surface radius (R32, blue) and relative volume of oil released from emulsions after centrifugation (HREL/HOIL, red).

\section{$154 \times 82 \mathrm{~mm}(150 \times 150 \mathrm{DPI})$}



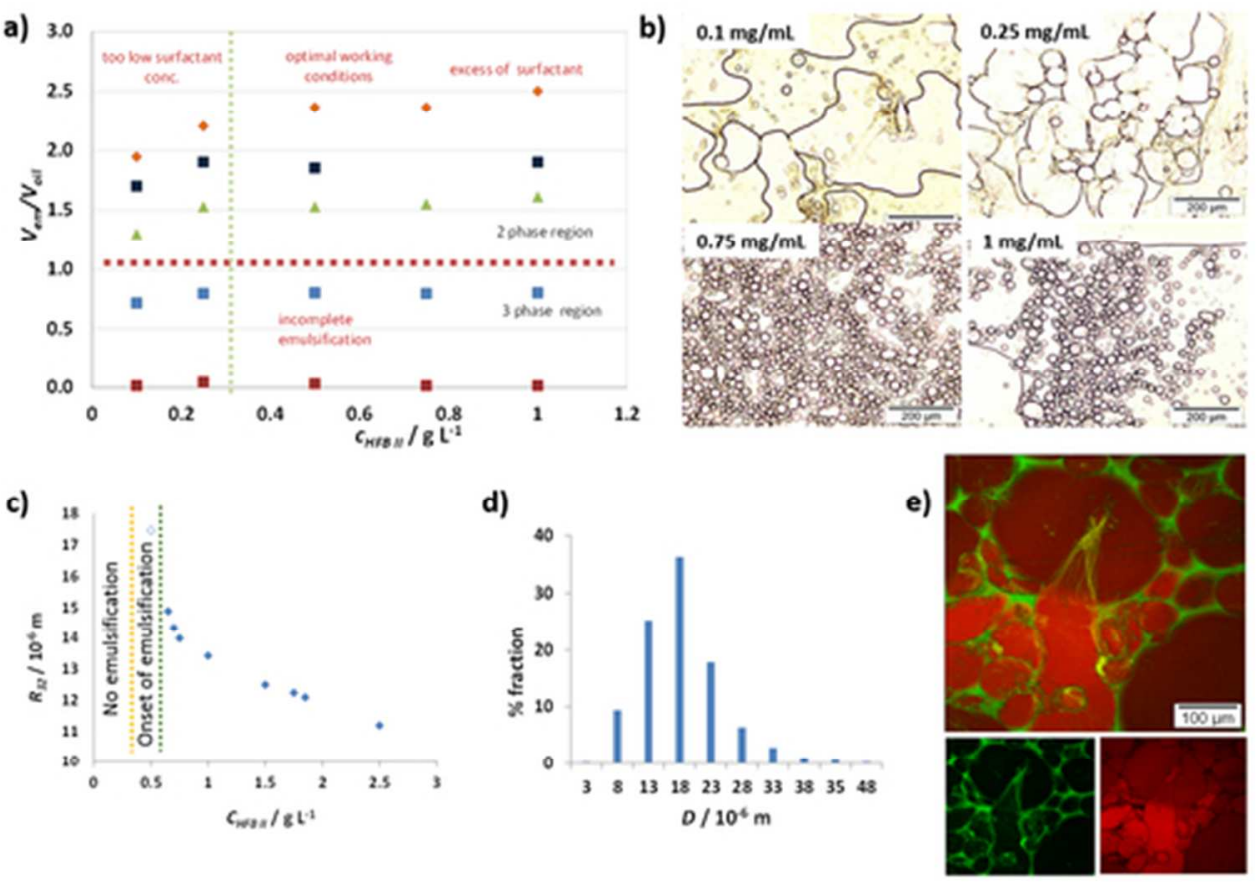

Fig. 6. a) Relative emulsion volume versus HFBII concentration for different w/o ratios: 90:10 ( $), 70: 30$ $(\mathbf{\bullet}), 50: 50(\mathbf{\Lambda}), 30: 70(\mathbf{\Delta}), 10: 90(\mathbf{-})$. b) Bright field microscopy images of 1:1 w/o mixtures with increasing HFBII concentrations. c) Mean volume-surface radius as a function of hydrophobin concentration. d) Average droplet size distribution for $1 \mathrm{mg} / \mathrm{mL}$ HFBII concentration. e) Confocal micros-copy images of 4:1 w/o emulsions with $1 \mathrm{mg} / \mathrm{mL}$ HFBII (green staining: protein; red staining: oil phase).

$44 \times 30 \mathrm{~mm}(300 \times 300 \mathrm{DPI})$ 
a)

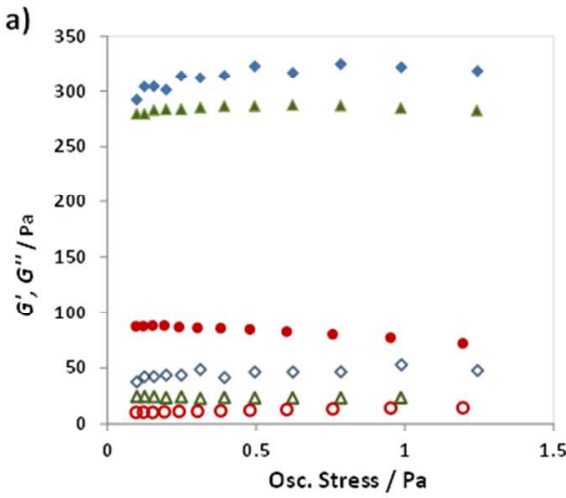

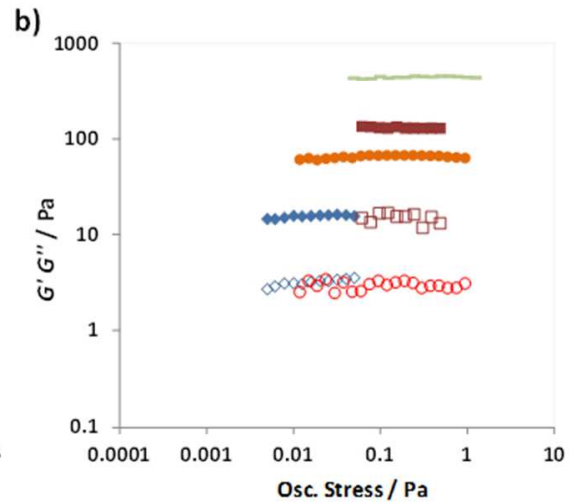

Fig. 7. Stress dependence of emulsion storage ( $\mathrm{G}^{\prime}$, solid symbols) and loss modulus ( $\mathrm{G}^{\prime \prime}$, empty symbols) in the near viscoelastic re-gion: a) comparison among different HFBII concentrations: $0.25(\bullet), 0.5(\mathbf{\Delta})$, and 1 $\mathrm{mg} / \mathrm{mL}(\bullet)$; b) comparison among different surfac-tants: Brij $1 \mathrm{mg} / \mathrm{mL}(\bullet), \mathrm{SDS} 2 \mathrm{mg} / \mathrm{mL}(\bullet), \mathrm{SDS} 3 \mathrm{mg} / \mathrm{mL}$ $(\mathbf{-})$, and HFBII $2.5 \mathrm{mg} / \mathrm{mL}(-)$.

$$
150 \times 67 \mathrm{~mm}(150 \times 150 \mathrm{DPI})
$$


Fig. 8. Phase behaviour diagram of the studied emulsions, as a function of protein concentration (CHFBII) and $\mathrm{w} / \mathrm{o}$ ratio.

\section{$79 \times 66 \mathrm{~mm}(150 \times 150$ DPI $)$}

